\title{
Is the Real Estate Market of New Housing Stock Influenced by Urban Vibrancy?
}

\author{
Alice Barreca (D), Rocco Curto, and Diana Rolando \\ Architecture and Design Department, Politecnico di Torino, Castello del Valentino, V. le Mattioli 39, Torino, Turin 10125, Italy \\ Correspondence should be addressed to Alice Barreca; alice.barreca@polito.it
}

Received 15 May 2020; Revised 26 August 2020; Accepted 18 September 2020; Published 22 October 2020

Academic Editor: Mohammad Swapan

Copyright (C) 2020 Alice Barreca et al. This is an open access article distributed under the Creative Commons Attribution License, which permits unrestricted use, distribution, and reproduction in any medium, provided the original work is properly cited.

\begin{abstract}
The attractiveness and vibrancy of an urban area are very complex aspects that both Public Administrations and real estate developers and construction companies have to carefully consider in order to correctly address their investments and sustainable urban development projects. The aim of this paper is to study urban vibrancy and its relationship with the neighbourhood services and the real estate market of new housing stock. Spatial analyses are performed to study the influence of the Neighbourhood Services Index (NeSI) and its Principal Components (PCs) on listing prices and the construction activity. Spatial autoregressive (SAR) models are applied both with lattice data and data points, in order to manage spatial dependence and to identify the variables that significantly influence housing prices and construction site density. Findings highlight that the NeSI significantly influences the real estate market of new housing stock and that above the analysed neighbourhood services and the retail activities have a great, significant, and positive influence on the density of housing construction sites. The results of this study represent a real support for both public and private bodies to identify the most and least attractive and vibrant urban areas and to deal with important aspects of urban complexity.
\end{abstract}

\section{Introduction}

Today, over half (55\%) the world's population live in urban areas, and it is estimated that $68 \%$ of it will be urban by the middle of the $21^{\text {st }}$ century. Trying to understand, predict, and shape the future development of cities requires competencies in analytical computational models and simulations, complex and cross thinking, and a forecasting attitude to mitigate radical changes and understand new development paths. Pivotal questions to be addressed are as follows: how the city is developing? In which kind of urban areas new housing stock is mainly developed? Which factors are able to influence the housing real estate market and the related choices of public and private investors? In this paper, we want to study the real estate market of new housing stock in a medium former industrial city in northern Italy, by analysing the urban complexity related to those factors able to make an urban area more or less attractive.

The concept of attractiveness of an urban area is a very crucial aspect that both public administrations and real estate developers and construction companies have to carefully consider in order to correctly address their investment decisions and development strategies. On the one hand, private companies need to identify those locations able to guarantee high profitability and minimize the risks related to the real estate market. On the other hand, public administrations are interested to identify the least attractive urban areas in order to improve them by means of specific infrastructural works or the activation of strategic regeneration projects. For these reasons, this study wants to support public and private bodies involved in cities development, by investigating if and how the attractiveness of an urban area can be related to urban vibrancy.

In the literature, the concept of urban vibrancy was initially introduced by Jacobs $[1,2]$ and related to the street life over a $24 \mathrm{~h}$ period. Subsequently, Montgomery [3, 4] related vibrancy to the crowd of streets or neighbourhoods in different moments during the day and night. Urban vibrancy (or vitality) was studied in several recent research studies that analysed the connection between urban spatial 
form and urban quality of life. Even though the definitions of urban vibrancy differ a little from each other, it is commonly recognized that urban vibrancy is closely associated with the attraction, diversity, and accessibility of a place [5] so that a proxy to measure urban vibrancy could be the presence of urban activity [6]. One dimension strictly related to the urban activity intensity is the presence of "Neighbourhood services," which conditions also the city physical features and the socioeconomic and living condition of their citizens. A recent study, in particular, studied urban vibrancy and its relationship with the neighbourhood services and the real estate market, by creating a Neighbourhood Services Index (NeSI) and spatially analysing its influence on the listing prices of existing housing [7]. Other studies analysed urban vibrancy, including the housing dimension [1-5], and investigated the presence of spatial correlation [6-10]. Nevertheless, in the literature, there are no investigations, at least to our knowledge, that spatially analyse urban vibrancy in relation to the real estate market of new housing stock.

Therefore, assuming the results achieved in [7], the aim of this paper is to understand how the Neighbourhood Services Index (NeSI) and its Principal Components (PCs), used as suitable proxies to measure urban vibrancy, can influence housing prices and construction dynamism in the real estate market of new housing stock.

In this study, it is assumed that urban vibrancy is defined by the high concentration and diversity of land-use configurations and services in a neighbourhood. Neighbourhood services include, among others, accessibility to public transport, local commercial activities, schools, cultural buildings (such as museums and theatres), and public green areas.

In this paper, the city of Turin is assumed as a case study, and widely recognized spatial dependence analyses and spatial regression models are performed [11]. We used both lattice data and spatial data points to analyse listing prices and construction sites density and to identify which buildings intrinsic, extrinsic, and locational attributes are able to affect housing prices and can represent attractive factors in the housing construction activity. The results of this study highlighted that urban vibrancy represents an important factor of urban complexity to be considered in the evolution of the attractiveness of an urban area: the NeSI, in fact, significantly and positively influenced both listing prices of new housing stock and the construction site density within the considered urban areas. In particular, the analysis of a set of neighbourhood services variables highlighted that especially the presence of retail activities significantly and positively influences the dynamism of the housing construction activity. Therefore, the results of this study can support both real estate developers and public administrations in dealing with important aspects of urban complexity and in identifying the most and the least attractive urban areas.

The paper proceeds as follows: the background of the analysis is introduced in Section 2, while Section 3 presents the methodological approach. Section 4 introduces the case study; results are discussed in Section 5; and some concluding remarks are presented in the final section.

\section{Background}

2.1. Urban Vibrancy. The interest in evaluating urban vibrancy has been progressively increased over the last few years, and different factors were used to quantitatively and qualitatively measure and evaluate it. Jacobs $[1,2]$ introduced, for the first time, the concept of vibrancy and described urban vitality in terms of street life over a $24 \mathrm{~h}$ period. Montgomery [3, 4] improved the original definition by specifying that urban vibrancy could be related to different land uses, and it could be described as the level of crowd of people in streets and neighbourhoods during different moments of the day and night.

Some recent studies $[5,6,12]$ used social media checkin data or numbers of mobile phone users in a $24 \mathrm{~h}$ period to analyse people's activities at different locations and time as a proxy of urban vibrancy. Wu et al. [13] confirmed that the value of housing properties is determined by a combination of characteristics defined as neighbourhood, locational, and structural attributes [14-16]. However, these attributes are referred to a specific submarket, so their specific value changes. In several studies, both the Geographically Weighted Regression method (GWR) and the hedonic pricing method (HPM) were used to explore the relationships between housing prices and marginal prices of specific attributes [17-21]. Moreover, traditional location theories indicate that properties located in proximity to commercial centres, green spaces, and other facilities commands have a higher marginal price [22]. For instance, a commercial centre serves as a place of employment, entertainment, shopping, and social contacting for most people. However, the presence of commercial centres and green spaces only has valueadded effects on housing prices over a certain range, and these effects vary across space.

Land use and facility layout significantly affected housing prices and urban vibrancy, and results potentially suggested that vibrancy can attract people, in many other realestate studies [23-25]. Ye et al. [6, 26] used small catering businesses to study economic vibrancy and focused on the effects of urban morphology. Jacobs-Crisioni et al. [27] and Yue et al. [6] measured mixed land use and its effects on vibrancy based on mobile phone data, and Li et al. [28] used the number of houses and consumption-related POIs to study the mechanisms of spatiotemporal variation.

2.2. Dynamism of Housing Construction Activity. Real estate market and cities building cycles have been increasingly influenced by economic downturns. To face the urban complexity increase, changes in the spatial configuration of land use, socioeconomic processes, and demographic dynamics, new perspectives are necessary in order to find which new rules underpin the new development dynamism by detaching and transforming classical paradigms. Particularly, it is fundamental to study the new spatial hierarchies defined by urban policies and real estate market trends and the emerging factors that are guiding social behaviours and purchasing criteria in the housing sector. 
In this paper, it is assumed that the construction site density is the main indicator of dynamism of housing construction activity and, consequently, a fundamental factor to be monitored and analysed to deal with urban complexity.

Zambon and Salvati [29] defined different urban phases of contemporary cities as time intervals featuring homogeneous economic, demographic, social, or institutional conditions. The Theory of Spatial Cycle (TSC) defined sequential stages of urban development allowing a general assessment of the recent history of contemporary European cities [30,31]. Four basic cycles were identified by assuming urban cycles that were defined by using econometric or mixed geographical approaches and that may reflect localscale transformations:

(i) Urbanization: related with settlement densification in central cities, population increase, and activities concentration [32]

(ii) Suburbanization: associated with new economic activities and residential settlements in peripheral rings and a rapid increase of population [33]

(iii) Disurbanization: related to the progressive loss of population and activities of inner cities and their more rapid decline of demographic and economic role than ring districts [34]

(iv) Reurbanization: with the reattraction of population and activities in the inner cities and subcentres and the consequent decline of suburbs [35]

Urban complexity interpretation may take into account these city transformation phases and clarify the role of socioeconomic factors in shaping selection, imitation, cooperation, and adaptation to change [29]. If, on the one hand, local housing markets are influenced by place-specific socioeconomic and cultural forces, on the other hand, real estate market dynamics are considered a pivotal factor affecting urban cycles, as well as urban functions and morphology [36-38]. Sequential waves of economic expansion and stasis influence sociodemographic trends, a largely variable productivity of the construction industry, weak housing policies, and family-oriented welfare regimes [32].

In a changing socioeconomic context, understanding the impact of urban building activities on spatial organization of urban areas and relative neighbourhoods is particularly interesting. In this regard, statistical indicators and spatial econometrics allow a wide-range assessment of the various dimensions at different scales (e.g., settlement morphology, building characteristics, metropolitan functions, and urban hierarchy). In particular, as the real estate market is widely argued as inefficient and incomplete as a result of the heterogeneity of products, high transaction costs, asymmetric information, limited arbitrage, and irrational investors [39-42], it is fundamental to find some factors able to positively influence the investors' behaviours and decision processes. Some of them, widely studied, are as follows: the rate of employment of urban big infrastructural transformation, the enhancement of urban quality, and the enhancement of energy efficiency that, to our knowledge, are aspects that are possible to be improved and deepened by new approaches and methodologies.

2.3. Spatial Econometrics and the Real Estate Market. Scholars widely studied econometric modelling to find the complete and definitive algorithm capable to predict prices of the real estate market by using socioeconomic and environmental factors, such as Morano et al. [43] who analysed how changes in land use represent important locational characteristics able to influence the formation of housing prices. Florax and van der Vlist wrote an extensive review of statistical models describing the relationships between housing prices and factors influencing them both at the national, regional, and local level [44].

Also, Chun-Chang et al. [45] studied the influence of a mass rapid transport (MRT) system on neighbourhood housing prices by performing spatial autoregressive lag and error models and considering 11 independent variables related to traffic service facilities, age of the buildings, construction, and unit characteristics. Results showed that, after synthesizing the positive and negative effects of the walking distance from an MRT station, the impact of a transfer station on housing prices within $500 \mathrm{~m}$ was negative during the time of construction, while it was positive as boosted accessibility.

Wittowsky et al. [46] performed both an OLS and a spatial autoregressive model (Spatial Lag) to study how a set of variables (including accessibility, "walk score," and socioeconomic characteristic of neighbours grouped in 10 milieus) influences the residential housing prices. The results showed that, in addition to the variables related the dwelling characteristics, the social dimensions of the neighbourhood are significant and have a different influence on price formation (the "Modern milieu" group had a positive coefficient and was correlated with higher prices, while the "Precarious milieu" one had a negative coefficient and was correlated with lower prices). Moreover, the adapted "Walk Scores," public transport indicators, and drive time to motorway access points varied in importance depending on the types of dwelling.

Yao et al. [47] analysed the spatial correlation and the spatial clustering by using data of building new housing in Zhengzhou; they found the presence of spatial dependence in housing prices and highlighted that spatial correlation patterns have space heterogeneity. Moreover, they demonstrated that even if spatial lagged effect is the most important factor in influencing housing prices in the spatial dimension, the transportation accessibility and the spatial spillover effect represent important factors that the government must consider in making controls on new building prices and in orienting real estate policies.

Chen et al. [48] proposed an integrated spatial econometric modelling approach, based on the application of multiple linear regression, spatial autocorrelation analysis, and GWR, to explore a series of factors at an urban level able to influence housing price changes in the 141 neighbourhoods in Guangzhou. The results showed that housing prices have significant spatial aggregation and highlighted the 


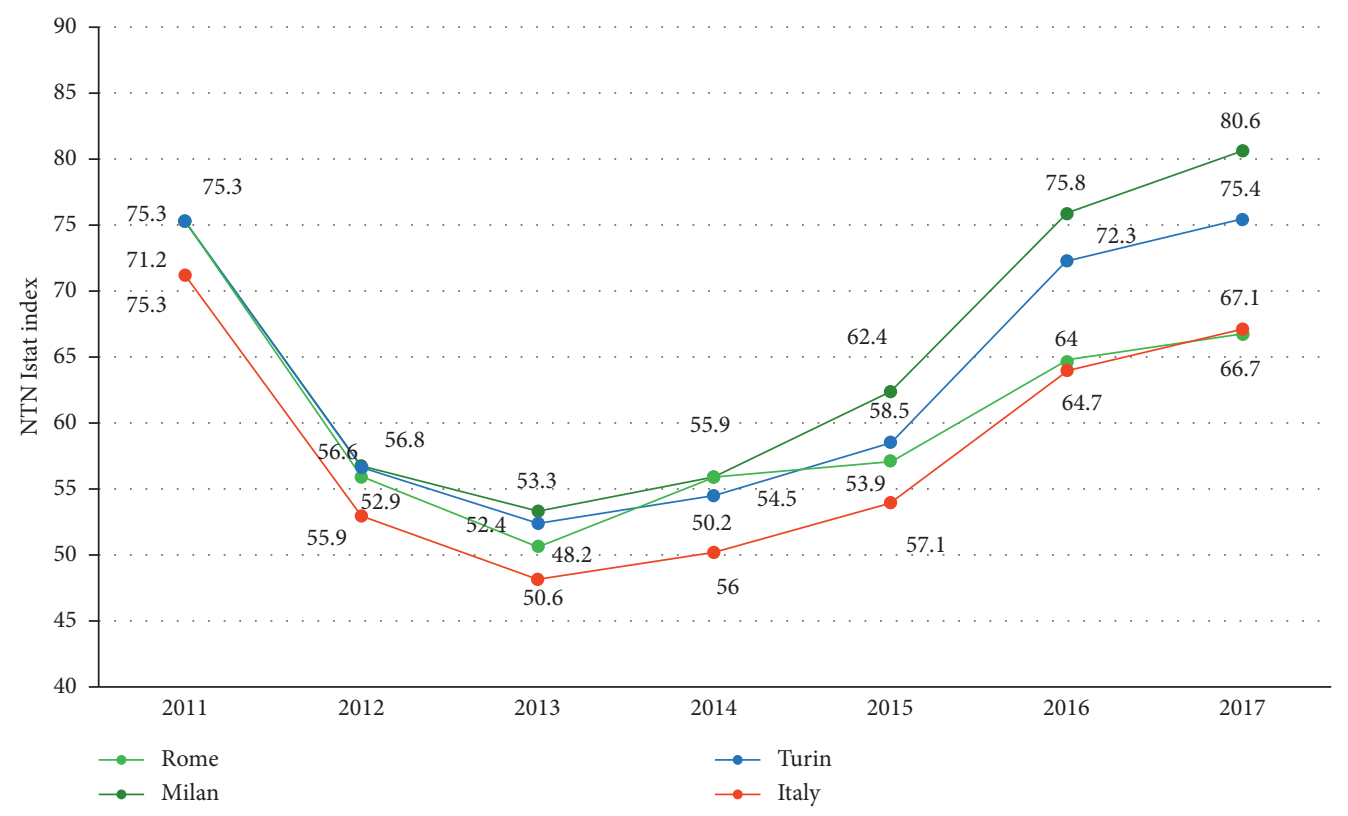

FIGURE 1: Index of the Normalized Transactions Number (NTN) in the principal Italian cities (source: authors' elaboration on OMI-Agenzia delle Entrate data).

location condition, the number of metro stations, and the road weighted density as the factors with the higher and positive influence on housing prices, while the density of restaurants has a negative impact on them.

Recently, other studies faced spatial econometrics in understanding house prices by using GWR, as in the work of Cellmer et al. [49] and Yuan et al. [50], or a model based on quantile regression as in the work of Mathur [51]. However, most of these studies concerned the existing buildings and the related market, trying to predict their value based on local extrinsic features.

In this study, the approach is different, since the aim isto address the issue of construction sites dynamism and housing prices of new buildings in relation to the concentration and diversity of neighbourhood services, which is, at least to our knowledge, a new topic that can contribute to growing the existing literature on the topic.

2.4. Urban Vibrancy and Real Estate Market in Turin. In Italy, the housing market suffered the effects of the economical crisis with a consistent decrease of values and number of transactions in the last nine years. The principal Italian cities differently reacted to these effects: Milan always represented the most dynamic market, followed by Turin and Rome. Figure 1 shows the Index of the Normalized Transactions Number (NTN), which, in 2014, reversed its negative trend.

Focusing on the trend of housing prices in the city of Turin, data of the Turin Real Estate Market Observatory (TREMO) highlight a general and significant decrease from 2011 to 2018, both for the existing housing stock and for the newly built and totally refurbished one. Although they have similar temporal trends and spatial distributions, they identify two different real estate market sectors that follow different rules and dynamics and, for this reason, have to be separately analysed (Figure 2).

The real estate market of the existing housing stock is widely studied and represents the main part of the housing stock in Italy [52-56]. In the city of Turin, although the number of transactions increased, listing prices of the existing housing stock significantly and constantly decreased from 2011 to 2018 ( $-25 \%)$, while the bargaining timing increased. The real estate market of the new housing stock also suffered a consistent fall in the prices from 2011 to 2018 $(-14 \%)$, but above all, a decrease of the total number of construction sites $(-30 \%)$ and a significant growth of the number of unsold housing units closely related to the shrinking of the number of transaction.

Currently, in Turin, the cyclical crisis of the real estate market seems to have become structural: the city is going through a disurbanization phase characterized by a series of economic, social, and demographic factors which are determining radical urban transformations both in the central and historical areas of the city and in other peripherical areas. Those important socioeconomic factors are changing the old urban hierarchies and, consequently, also the real estate submarkets (in terms of dynamism and price trends) and their territorial boundaries. The great influence of the location variable in the housing price determination process and in influencing buyers' and sellers' behaviours is widely recognized. Currently, the location paradigm is evolving by assuming different parameters; the preferences related to the location characteristics and neighborhood services are changing, and this mutation is going to identify new territorial hierarchies and new real estate submarkets. In this 


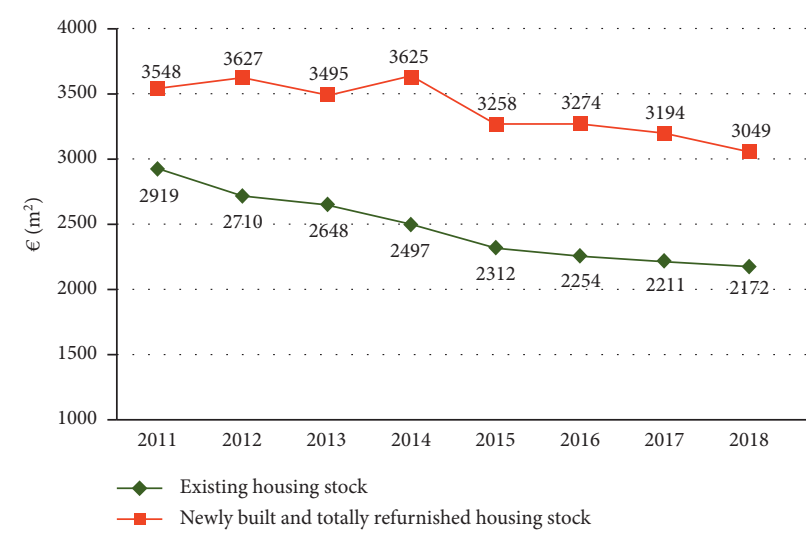

(a)

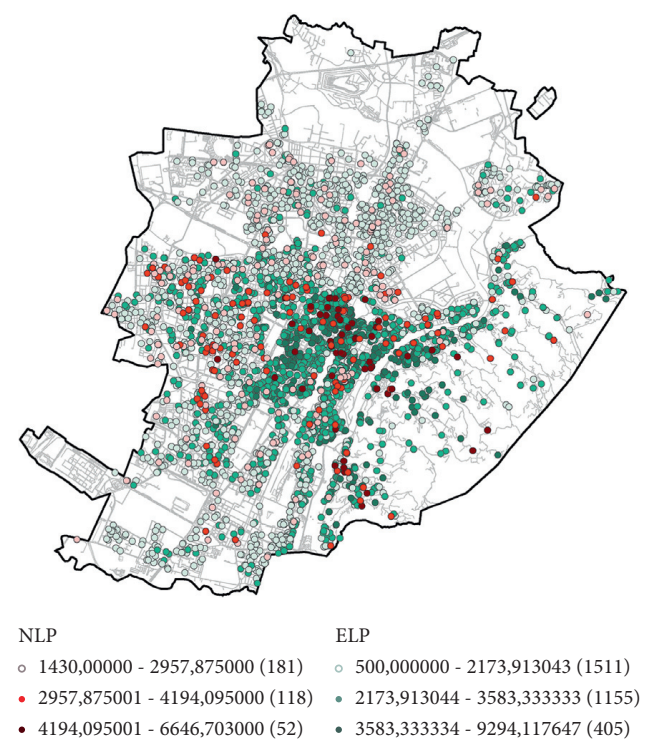

(b)

FIGURE 2: Existing housing stock and newly built and totally refurbished housing stock: listing prices mean temporal trend 2011-2018 (a); listing prices mean spatial distribution (b) (source: authors' elaboration on TREMO data).

regard, the case of the hill side of the city of Turin is emblematic since, for several years, it was considered a prestigious, classy, and expensive area due to its environmental amenities and housing typologies (villas), but currently, the housing price trend continues to decrease.

In this context, urban vibrancy seems to effectively represent a proxy of the location variable, being able to evidence important changes in the potential buyers' behaviours, as well as to influence the investment decisions of key public and private subjects. Therefore, the analysis of the urban vibrancy factors can effectively support the complex identification and the interpretation of new emerging territorial hierarchies in this crucial development phase of the city. The socioeconomic and urban transformations processes that emerge by analysing the relationship between urban vibrancy and the real estate market can highlight the attractiveness of urban areas and support the interpretation of the location variable in a new way.

The real estate market of the existing housing stock and its relationship with urban vibrancy were analysed by authors in a sister paper [7], by creating a Neighborhood Services Index (NeSI) as a proxy of urban vibrancy. In that study, the city of Turin was assumed as a case study, and ESDA results showed that a correlation between urban vibrancy and housing prices of existing buildings exists. To manage the spatial dimension of the hedonic model, spatial autoregressive models (SAR) were applied, and the results highlighted that the NeSI had a partial but positive influence on housing prices, with particular reference to those variables related to cultural offerings. The city of Turin was spatially analysed, and results showed the presence of spatial clusters of low housing prices and low vibrancy values in the northern part of the city and the presence of vibrant areas characterized by high real estate values in the central and historical part of the city. On the contrary, the hill side of the city, which is one of the most luxurious areas of the city, emerged as one of the least vibrant areas of the city, due to a lack of public transport connections with the city centre, a total absence of urban services, a general isolation from urban cultural activities, and a lack of shops for basic necessities. Another case where urban vibrancy and the real estate market were not correlated is a specific neighborhood in the city centre, characterized by low housing prices and a high concentration of neighborhood services, as well as by a high density of people with a low education level, foreigners, and temporary residents.

Therefore, Barreca et al. [7] outlined that if, on the one hand, urban vibrancy acts as a multiplier of property prices of existing housing stock in the central and historical areas of the city, on the other hand, urban vibrancy does not significantly influence housing prices in the most vulnerable areas of the city, where the real estate market is mostly and negatively influenced by social and housing factors [9]. In conclusion, the analysis of the relationship between urban vibrancy and the real estate market of the existing housing stock highlighted that this phenomenon has to be spatially analysed since results changed on the basis of the specific features of each particular urban areas, the different segments of the population, and their behaviors in the market.

The real estate market of the new housing stock represents a different real estate market sector, characterized by a lower number of housing units listed in the market and also by a lower number of transactions. Although it is numerically less consistent than the real estate market of the existing housing stock, it is characterized by higher housing prices and reflects important strategies and dynamics in the city urban development. Therefore, it represents a complex market sector to be analysed by taking into account both the potential buyers' and the urban developers' perspectives. In fact, the housing price levels are influenced by the willingness to pay of a restricted segment of population and by 
the strategic decisions of construction companies and real estate developers. Therefore, this market sector is conditioned by different rules and dynamics, so that it deserves to be analysed considering not only the housing price variable but also the construction site density.

The relationship between urban vibrancy and the real estate market of the new housing stock has not been studied, at least to our knowledge, in the Italian context. Therefore, this study wants to fill the gap by analysing if and how urban vibrancy spatially influences the real estate market of new housing stock, by considering its relationships both with prices and construction activity dynamism throughout the city and by investigating if it could condition buyers' behaviours and act as an investments attractor. This represents a crucial aspect to be investigated in a broader analysis aimed to study the city's development cycle assuming a spatiotemporal perspective.

\section{Methodological Approach}

A methodological approach was developed to study the urban vibrancy in relation to the real estate market. It was based on the application of Principal Component Analysis (PCA) to create a Neighbourhood Service Index (NeSI) and on the application of widely recognized methods of spatial analyses and spatial regression models. A first application is described in the abovementioned sister paper [7] aimed to study urban vibrancy, its relationship with neighbourhood services, and the real estate market of existing housing stock. The results of that previous research lay the ground for new analyses finalized to investigate the relationship between urban vibrancy and the real estate market of the new housing stock.

In this research, the same methodological approach, based on four steps, has been applied on a new data sample related to new building stock: data sample (step 1), dimension-reducing procedure by means of Principal Component Analysis (PCA) (step 2), Exploratory Spatial Data Analysis (ESDA) (step 3), and spatial autoregressive models (step 4).

\subsection{Step 1. Housing Prices and Neighbourhood Services POIs} Geographical Database. A GIS based on different geodatabases was developed, including more than 300 variables regarding both existing and new building stock in the time period 2011-2018. Data (mainly open) were collected from four principal sources. Listing prices and the extrinsic and intrinsic buildings features were collected from the Turin Real Estate Market Observatory (TREMO) database (http://www.oict.polito.it/en/). The TREMO was established in 2000 in a collaboration between University (Politecnico di Torino) and the Municipality of Turin and, yearly, monitors and analyses the residential real estate market of the city of Turin [57]. Population characteristics were collected from the ongoing survey of the Italian National Institute of Statistics (ISTAT) (https://www.istat. it/en/) and the POIs of the urban built and green environment from geoportals of the Municipality of Turin (http://geoportale.comune.torino.it/web/) and Piedmont Region (http://www.geoportale.piemonte.it/cms/) (Figure 3).

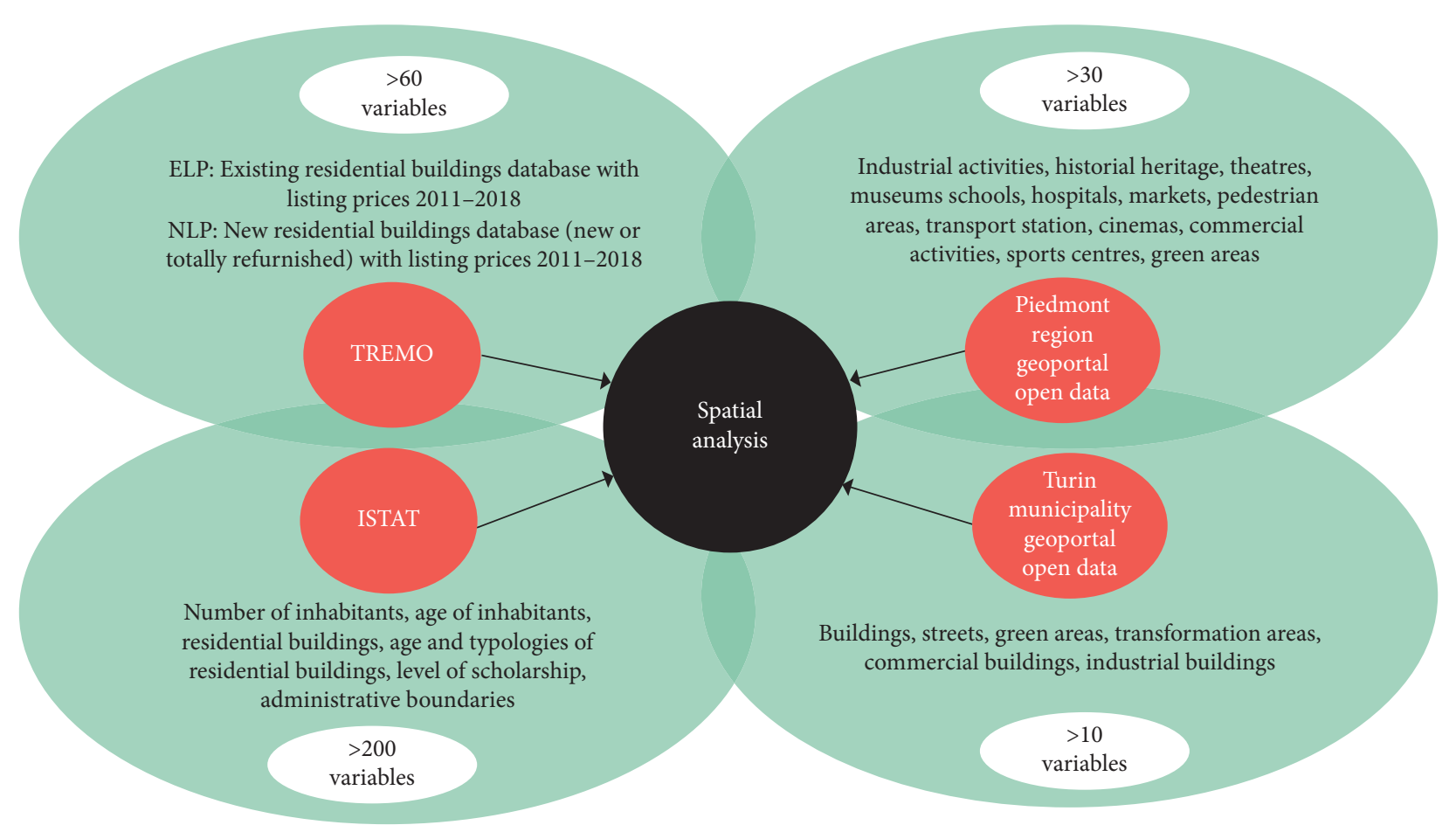

FIgURE 3: Multisources data for spatial analyses (source: authors' elaboration). 
3.2. Step 2. A Dimension-Reducing Procedure: Principal Component Analysis (PCA). A series of variables were defined, standardized by means of the $z$-scores method, and clustered by means of the Principal Component Analysis (PCA). PCA is used as a dimension-reducing procedure, for the collection of continuous variables, identifying linear combinations of the original variables in the form of a small set of orthogonal components (synthetic variables), called eigenvectors or factors, which explain most of the total (PCA) variations present in the original variables. PCA is a different steps procedure based on an $n \times p$ data matrix, $X$, with a columnwise zero empirical mean. The full principal components decomposition of $X$ can be given as follows:

$$
T=X W
$$

where $W$ is a $p$-by- $p$ matrix of weights whose columns are the eigenvectors of $X^{\mathrm{T}} X$. Columns of $W$ multiplied by the square root of corresponding eigenvalues, that is, eigenvectors scaled up by the variances, are called the loadings of the PCA. Subsequently the computation of a covariance matrix (2) enables to identify the more or less variable indicators and those that covary in a positive or negative way or for which ones it is not a predictable relationship.

$$
\operatorname{cov}(X, Y)=\frac{1}{n-1} \sum_{i=1}^{n}\left(X_{i}-\bar{x}\right)\left(Y_{i}-\bar{y}\right) .
$$

In the results, the first component is always the linear combination that explains the major variability among original input data, while starting from the second component, progressively, the remaining variation is explained.

3.3. Step 3. Exploratory Spatial Data Analyses (ESDA). Exploratory spatial data analyses were carried on two different datasets: the first one constituted by spatial data points (related to the construction sites active in the considered time period) and the second one constituted by lattice data to analyse the density of construction sites and neighbourhood services within defined boundaries.

Linear and nonlinear correlation were investigated on the whole data sample by means of Pearson and Spearman correlation tests. The presence of spatial autocorrelation was investigated by calculating Moran's Index, and the classification types were spatialized by Local Indicator of Spatial Association (LISA) clusters maps.

Spatial autocorrelation needs to be investigated because it normally affects the real estate market [58] and, if not properly processed, may affect regression models making them misleading [59]. Spatial autocorrelation is also a measure of spatial dependence that arises in lattice data, whereby the correlation occurs among contiguous units $[60,61]$.

The standardized $z$-score of Local Moran's I provides an assessment of spatial autocorrelation, by assessing the similarity of each observation with those in its surroundings, for each location [58-62]. Local Moran's Index can be written as follows:

$$
I_{i}=z_{i} \sum_{j} w_{i j} z_{j}
$$

where $z_{i}$ is the standardized spatial weight and the summation over $j$ is such that only neighbouring values $j \in J_{i}$ are included. For ease of interpretation, the weights $w_{i j}$ may be in row-standardized form, and by convention, $w_{i i}=0$.

Results of Local Moran Index in the Scatter Plot permit to identify spatial clusters, giving no information on their significance and position, but providing a classification of spatial association in the following four categories: spatial cluster "high-high" or "hot spots," defined by high values of the investigated phenomenon with a high level of similarity with their surroundings; spatial cluster "low-low" or "cold spots," defined by observations with low values and a high level of similarity with its surroundings; spatial outliers "high-low," defined by observations with high values surrounded by low ones; and spatial outliers "low-high," defined by observations with low values surrounded by high ones.

3.4. Step 4. Spatial Regression Models and Residuals Analysis. A common characteristic of spatial data sets is the spatial nonstationarity which refers to a condition in which some sets of variables over space are not structurally stable. Scholars have argued that the spatial global model and local ones can differently overestimate or underestimate values in different submarkets, and the global autoregressive models can manage the spatial component of prices to make the regression model unbiased. A useful approach for examining spatial nonstationarity consists in estimating separate hedonic equations into different areas belonging to different submarkets. Various spatial econometric methods have been widely applied, and all the abovementioned local spatial models have been widely employed, such as geographically weighted regression (GWR) which allows different relationships between variables to exist at different points in space.

In this research a global regression model was chosen to perform a preliminary and explorative analysis aimed at investigating the existence of a relationship between urban vibrancy and construction activity in the real estate market of the new housing stock and comparing the results with those achieved in a previous study on property listings of existing buildings. Moreover, in this research, the construction companies' global perspective is assumed in identifying and choosing the urban areas where housing investments could be undertaken or, on the contrary, the public administration perspective in selecting the less equipped urban areas that necessitate to be redeveloped to foster the real estate market.

Therefore, in this research, different spatial autoregressive models were performed: firstly, we analysed the square meter housing prices (NLP- Euro/ $\mathrm{m}^{2}$ ) as a dependent variable and a set of extrinsic and intrinsic building characteristics as independent variables, by using data points; secondly, we performed OLS and spatial models assuming 
the construction site density (CSD) as a dependent variable, by using lattice data.

In the first case, a logarithmic transformation of the dependent variables was applied, to weaken the collinearity, eliminate heteroscedasticity, and reduce the absolute values of the data. Firstly, in both cases, Ordinary Least Squares (OLS) models were tested to verify the pertinence of used variables by means of the Jarque-Bera test (normality of errors) and Breush-Pagan and Koenker-Bassett tests to verify the absence of heteroskedasticity [63]. The presence of spatial effects (or spatial heterogeneity) as measures of the similarity between values associations (covariance, correlation, or difference) and associations in space (contiguity) $[11,64]$ was tested by means of Moran's test and the Lagrange Multiplier tests (LM-lag and LM-error) [65] which also indicated the possible spatial model to be used (SLM or SEM). Spatial autocorrelation statistic is considered significant when it assumes an extreme value, compared to what would be expected from the null hypothesis (absence of spatial autocorrelation).

In this study, two spatial regression models, namely, the Spatial Lag Model (SLM) and Spatial Error Model (SEM), were performed to correctly manage the error correlation due to spatial effects [66-68].

Formally, if a standard OLS has the following form, we can define the error term $\varepsilon_{i}$ in two different ways for the SLM or SEM.

$$
y_{i}=X_{i} \beta+\varepsilon_{i} .
$$

The Spatial Error Model can be specified as

$$
y_{i}=X_{i} \beta+\lambda w_{i} \varepsilon_{i}+u_{i},
$$

where $u_{i}$ is the random error (independent identically distributed- i.i.d.), and the spatially structured error is composed of the added spatial error coefficient, $\lambda$, and the original $\epsilon$ error term weighted by a weight matrix $w_{i}(W)$. If there is no spatial correlation between errors, then $\lambda=0$. If $\lambda \neq 0$, OLS is unbiased and consistent, but the standard errors will be wrong and the $\beta$ will be inefficient. Otherwise, the Spatial Lag Model can be specified as

$$
y_{i}=X_{i} \beta+\rho w_{i} y_{i}+u_{i},
$$

where $X_{i}$ is a matrix of observations on the explanatory variables, $\rho$ is the spatial coefficient, and $w_{i} y_{i}$ is the spatially lagged dependent variable for weights matrix $w_{i}(W)$. If there is no spatial dependence and $y$ does not depend on neighbouring $y$ values, then $\rho=0$. Rho $(\rho)$ reflects the spatial dependence inherent in our sample data by measuring the average influence on observations by their neighbouring observations. If $\rho$ is significant, in this case, OLS is both biased and inconsistent.

\section{Data Description}

4.1. Listing Prices of New Housing Stock and Construction Site Density Summary Statistics. To analyse housing prices of new housing stock and the construction site density in Turin, we used a sample of 2394 property listings of new housing stock offered in Turin between 2011 and 2018, which refer to 351 construction sites. This sample was selected from a whole database of 12590 housing units located in new or totally refurbished buildings and listed on the market from 2003 to 2018. These data were collected by the TREMO by means of a structured data collection procedure that included continuous monitoring of real estate ads published on the main Italian real estate web platforms, data refinement and increase by verification and comparison of the offers on the principal contractor website, meeting with the contractors, and visiting the sales offices at the construction sites.

The real estate market of new housing stock was analysed by considering both listing prices of the new housing units (NLP) and the construction sites density (CSD).

We calculated the mean housing prices per square meter (NLP- Euro $/ \mathrm{m}^{2}$ ) for each construction site of the sample (351), by taking into account only ordinary new housing units (central floors, no terraces, and no gardens). Therefore, by this way, the new sample related to the construction sites can be considered homogeneous and related values can be considered comparable. It is clear that the variability of the sample and the subsequent model has been reduced, but this choice is consistent with this research purpose, which is aimed to better understand how the characteristics of the building, the site, and the neighbourhood vibrancy affect each construction site mean price.

CSD and lattice data were computed by assuming Statistical Zones (SZ) boundaries, defined by ISTAT with the objective to divide the urban areas in homogeneous parts, by using the main infrastructures and rivers of the city as boundaries able to define both different submarkets [9] and different sets of neighbourhoods. One key limitation of this paper is the unavailability of transaction prices, due to the absence of transparent information of the real estate market in the Italian context; nevertheless, previous studies demonstrated that listing prices can be considered a good proxy of transaction prices [50] (Table 1).

After the elimination of outliers and observations with missing location, the data sample consisted of 2394 property listings (mean price $=3367 \quad$ Euro $/ \mathrm{m}^{2}$; standard deviation $=1227 \mathrm{Euro} / \mathrm{m}^{2}$ ). The construction site density in the ZS mean is 4.5 construction sites $/ \mathrm{km}^{2}$ by ZS, with a high standard deviation because, in some areas of the city, there was no transformation during the considered time period ( 8 years).

Focusing on the typologies of the analysed construction sites, the dataset can be split into two subsamples: new buildings (NCSTYP1) and totally refurbished ones (NCSTYP2). Since Turin is a historical city, the most part of the prestigious and central areas of the city are already occupied by classy and, sometimes, listed residential buildings, mainly condominium of 5 or more floors. The mean price of the sut subsample reflects different features of existing buildings totally refurbished and newly constructed ones: the NCSTYP2 mean price is $3425 \mathrm{Euro} / \mathrm{m} 2$, while for NCSTYP1, the mean price is $3038 \mathrm{Euro} / \mathrm{m} 2$, respectively, higher and lower than the global mean of the city. NCSTYP1 represents the $51 \%$ of the construction sites of our sample, 
TABLE 1: Summary statistics of the housing prices and neighbourhood service variables (source: author's elaboration on TREMO data).

\begin{tabular}{|c|c|c|c|c|c|c|}
\hline Dimensions & Definition & Min & Mean & Max & St. dev & Median \\
\hline $\mathrm{NLP}$ & Listing price of new housing stock & 1330 & 3367 & 10462 & 1227 & 3048 \\
\hline CSD & Construction sites density (by SZ) & 0 & 4.558 & 13 & 2.941 & 4 \\
\hline NLPTYP1 & Newly constructed building & 1740.171 & 3.039 & 5.781 & 734 & 2.870 \\
\hline NLPTYP2 & Totally refurbished building & 1.430 & 3.425 & 6.647 & 1.260 & 3.128 \\
\hline A1 & 2011 & 1839 & 3403.839 & 6453 & 1064.728 & 3034 \\
\hline $\mathrm{A} 2$ & 2012 & 1983 & 3307.649 & 6072 & 882.4756 & 3075 \\
\hline A3 & 2013 & 1984 & 3108.885 & 6117 & 960.9618 & 2834.5 \\
\hline A4 & 2014 & 1740 & 3478.021 & 6545 & 1222.888 & 3242 \\
\hline A5 & 2015 & 1430 & 2921.18 & 6647 & 830.4901 & 2865 \\
\hline A6 & 2016 & 1569 & 3151.644 & 6310 & 1058.208 & 2819 \\
\hline A7 & 2017 & 1849 & 2829.656 & 5033 & 648.7991 & 2734 \\
\hline A8 & 2018 & 1596 & 2939.667 & 4722 & 777.927 & 2745 \\
\hline $\mathrm{C} 1$ & Economic & 1430 & 2408.307 & 3483.333 & 555.0733 & 2384.037 \\
\hline $\mathrm{C} 2$ & Medium & 1568.769 & 2878.867 & 5581.342 & 662.1211 & 2766.986 \\
\hline C3 & Noble & 2359.944 & 3956.494 & 6309.829 & 1001.14 & 3839.852 \\
\hline $\mathrm{C} 4$ & Prestigious & 2798.385 & 4955.83 & 6646.703 & 1261.243 & 4718.592 \\
\hline BP0 & No box or park & 1430 & 3129.04 & 6309.829 & 1004.688 & 2838.506 \\
\hline BP1 & Box and park & 1756.838 & 3261.671 & 6646.703 & 986.8983 & 2992.91 \\
\hline PC1 & Retail activities density (by SZ) & -0.946 & 0.45774 & 3.940842 & 1.154596 & 0.151633 \\
\hline PC2 & Cultural offer density (by SZ) & -1.10755 & -0.03466 & 4.865378 & 0.945161 & -0.24933 \\
\hline PC3 & Transport density (by SZ) & -1.44361 & 0.015129 & 8.038499 & 1.088579 & -0.22937 \\
\hline PC4 & Public green and sport areas density (by SZ) & -1.33781 & 0.032744 & 4.215549 & 0.861926 & -0.22686 \\
\hline PC5 & Healthcare density (by SZ) & -3.00842 & -0.01835 & 4.161631 & 0.950893 & -0.21812 \\
\hline $\mathrm{NeSI}$ & Neighbourhood services index (by SZ) & -3.14844 & 0.452604 & 7.601669 & 2.014646 & 0.08349 \\
\hline
\end{tabular}

related to newly constructed buildings, built on free land parcels or at the place of demolished buildings, while the $49 \%$ is NCSTYP2 (Figure 4).

Figure 4 shows that the totally refurbished buildings (green points) are concentrated in the city centre, the historical part of the city, and along the metro line 1; while new buildings (red points) are mainly sited in the first ring around the centre. Furthermore, analysing dots size, representing dimensions of the construction sites (number of housing units), it can be seen that larger yards are located in the city centre, while smaller yards are located in the west and north part of the city.

Focusing on the construction year of the analysed construction sites, the dataset can be split into 8 subsamples. Figure 5 shows that the highest listing prices of new housing stock were stable in the city centre during the considered time period. On the contrary, the new housing stock characterized by medium level listing prices changed its location over the last 8 years, moving from the northwestern part of the city to the southern and the southeastern part of the city.

It is also possible to notice how, in 8 years, urban hierarchies changed: some urban areas that, in 2011, were characterized by the highest listing prices (dark red coloured), in 2018, presented drastically lower values. This trend is even more evident looking at the spatial distribution of the construction sites density in the city over the considered time period: in fact, the number of construction sites decreased from 95 in 2011 to 54 in 2018 (Figure 6).

Spatial distribution of construction site density by ZS shows that, in 2011, despite the total number of ZS affected by, at least, one construction site was not much higher than in $2018(+12 \%)$, the construction sites were spread in a larger part of the urban area. Otherwise, in 2018, the construction activity was much more clustered, and it was present mainly along the metro line 1, opened in 2006.

4.2. The Neighbourhood Services Index (NeSI) and Its 5 Principal Components (PCs). To analyse the density of neighbourhood services as a proxy of urban vibrancy, we used different geodatabases to compute 43 variables based on different POIs. Table 2 shows the summary statistics of the density of these POIs, measured for each SZ and clustered by means of PCA for the formation of the NeSI (landmarks, transports, cultural offerings, retail activities, residential sector, public green areas, sport buildings, education institutions, and healthcare centres).

Principal Components Analysis (PCA) considered meaningful about 20 variables that were aggregated in 5 Principal Components (PCs) able to explain the $80 \%$ of the variance. The 5 PCs represented the following neighbourhood services dimensions: Retail, Cultural Offer, Public Transports stations, Public Green and Sports Areas, and Public Healthcare. In Figure 7, their spatial distribution is represented by means of heat maps.

As shown in Figure 7, the Retail POIs (PC1) are mainly concentrated in the city centre, with a good distribution in the western and southern part of the city, and the Cultural Offer POIs (PC2) are otherwise mainly concentrated only in the city centre with many peripherals areas with a very low level. A totally different distribution is also shown for the 


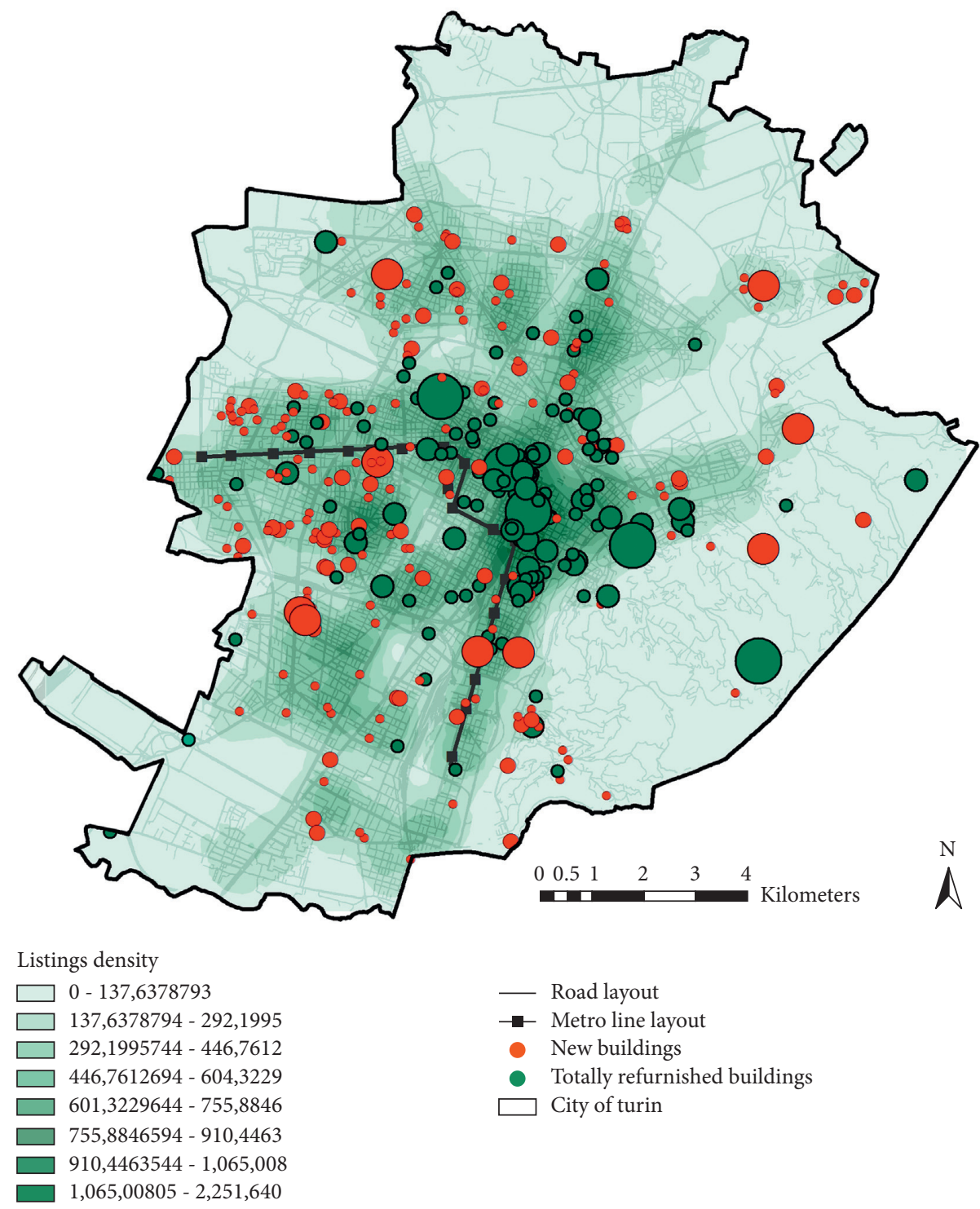

FIgURE 4: Housing construction sites in the city of Turin in the 2011-2018 time period divided in new buildings (CSDTYP1) and totally refurbished buildings (CSDTYP2). The diameter of points is proportional to the number of housing units of each site (source: authors' elaboration).

Public Transports (PC3), which includes only POIs of the metro lines and railway stations, and bus stops are excluded because homogeneously covers all the urban area. Finally, the Public Green and Sport Areas (PC4) are concentrated mainly along the rivers of the city, while the last component representing the Public Healthcare POIs (PC5) represents the main hospitals and related services of the city.

By a linear sum of the eigenvalues of the five components, the Neighbourhood Services Vibrancy Index (NeSI) was calculated with no a priori assumptions about the importance of each dimension in the overall sum (adopting equal weights). The NeSI is able to measure the density of neighbourhood services in the $94 \mathrm{SZ}$, and it is a suitable proxy to measure urban vibrancy. Spatial distribution of the $\mathrm{NeSI}$ is shown in Figure 8 jointly with listings prices and construction site density values for the considered time period.
Since the listings sample represents the whole data universe of the new housing stock in Turin, the 16 statistical zones with no data were effectively urban areas with no construction sites in the 8 years considered. Moreover, areas bordered in black have a low number of residential buildings, since they mostly consist of nonconstructed areas (parks, railway, or industrial areas). Figures $8(\mathrm{a})$ and $8(\mathrm{~b})$ show that the city is divided into two main patterns. The highest listing prices are mainly concentrated in the central and hillside zones, which are the oldest and most classy areas of the city and which mainly correspond also to the more densified constructed city area. The second pattern runs all around the city centre, and it is characterized by a mediumhigh construction site density and included housing prices rather low. Some physical barriers such as Corso Francia and Corso Regina Margherita, principal infrastructure axes in the north part of the city, are perceived as borders between 


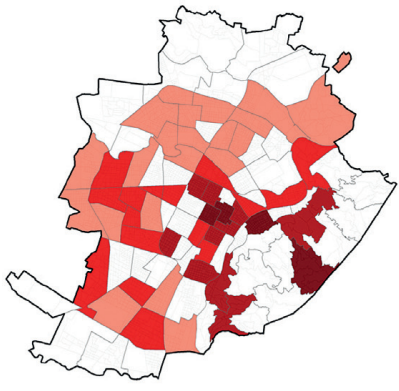

(a)

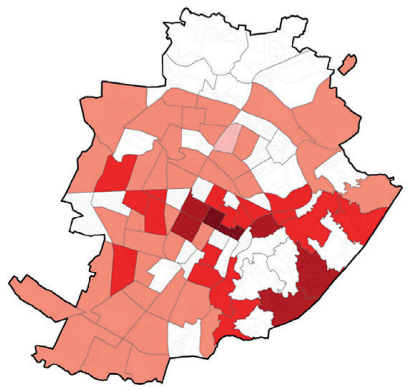

(e)

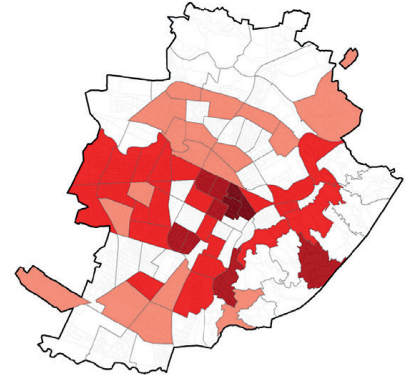

(b)

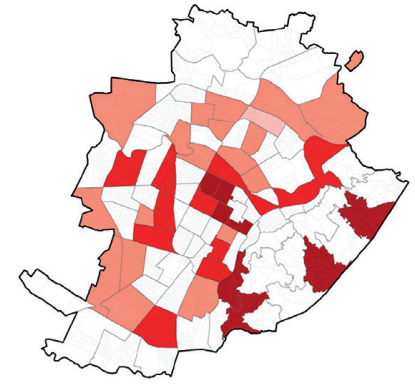

(c)

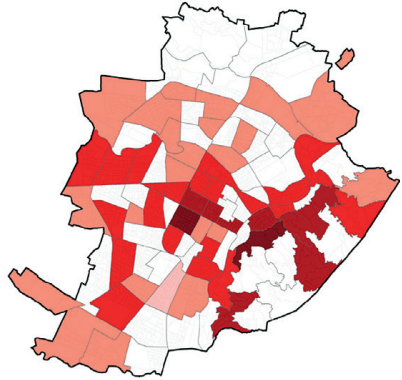

(d)

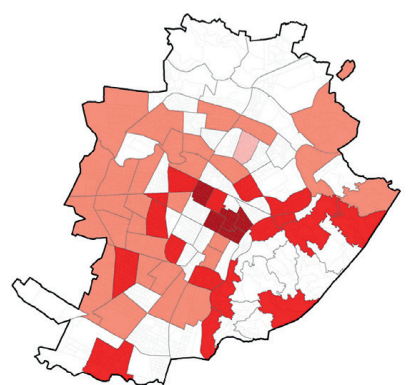

(f)

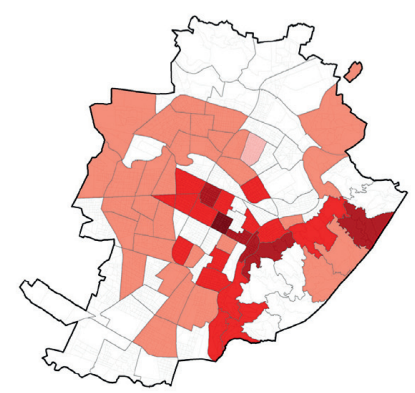

(g)

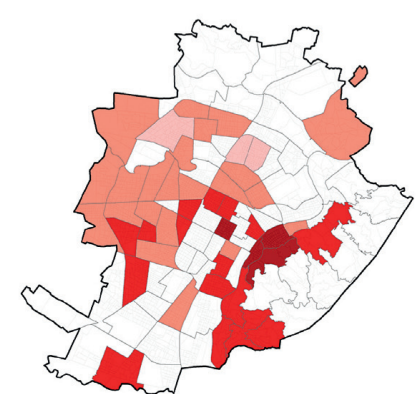

(h)

Listing prices mean
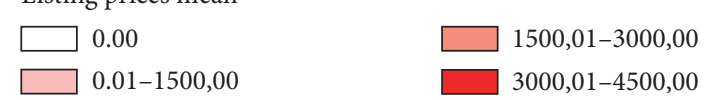

$4500,00-6000,00$

$6000,01-7500,00$

Figure 5: Construction sites mean listing prices of new housing stock (NLP) (source: author's elaboration). (a) 2011 . (b) 2012 . (c) 2013. (d) 2014. (e) 2015. (f) 2016. (g) 2017. (h) 2018.

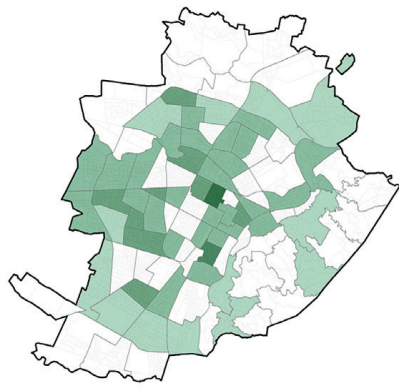

(a)

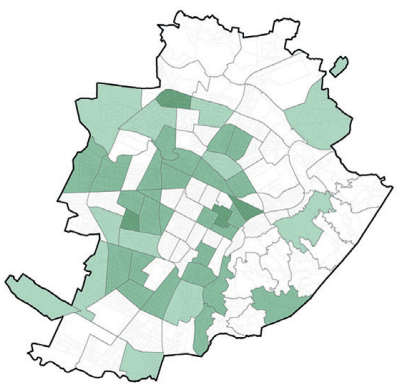

(e)

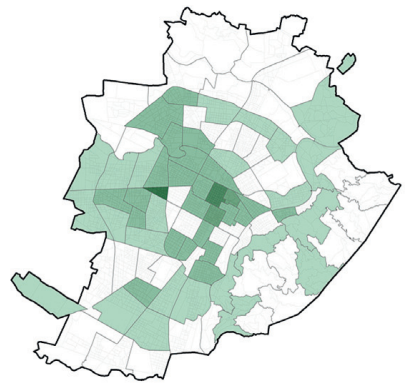

(b)

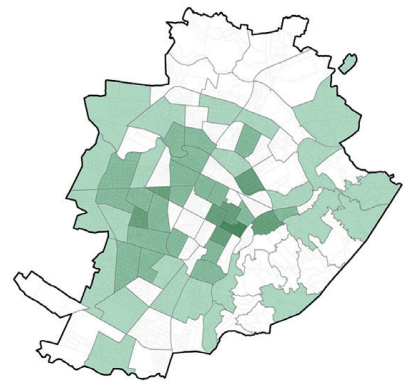

(f)

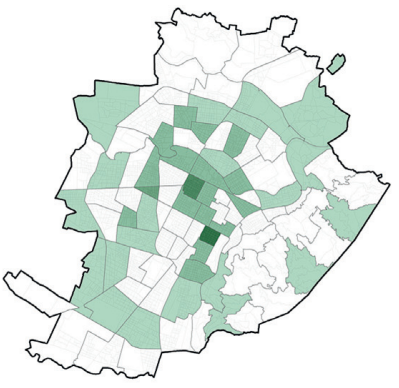

(c)

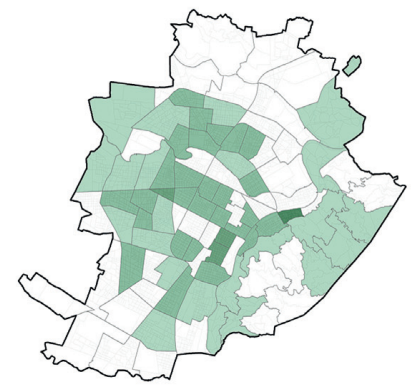

(g)

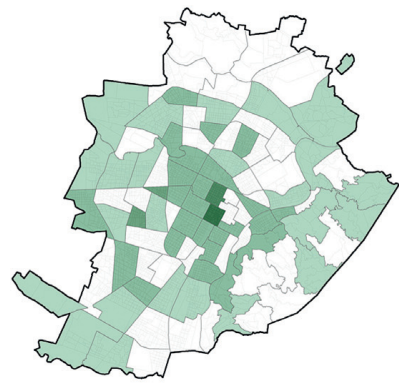

(d)

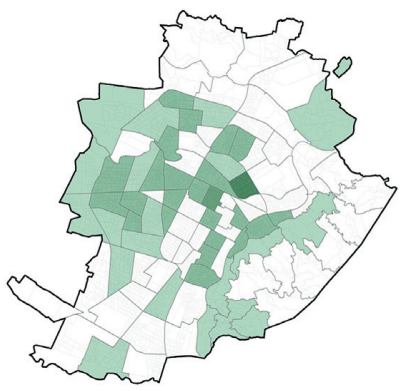

(h)

Construction sites density

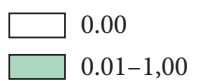

Figure 6: Construction Sites Density (CSD) (source: author's elaboration). (a) 2011. (b) 2012. (c) 2013. (d) 2014. (e) 2015. (f) 2016. (g) 2017. (h) 2018. 
TABLE 2: Summary statistics of neighbourhood service variables. Data sources: (a) TREMO data, (b) ISTAT open data, (c) Municipality of Turin Geoportal Open Data, and (d) Piedmont Region Geoportal Open Data (source: author's elaboration).

\begin{tabular}{|c|c|c|c|c|}
\hline Dimensions & POIs definition & Source & Mean & St. dev \\
\hline \multicolumn{5}{|l|}{ TOPOGRAPHY } \\
\hline SZ_SKM & Area of each SZ in $\mathrm{km}^{2}$ & (c), (b) & 1.383 & 1.019 \\
\hline BLD_SKM & Density of buildings & (c), (d) & 409.991 & 288.166 \\
\hline POP_SKM & Density of residential population & (b) & 9368.274 & 7118.101 \\
\hline \multicolumn{5}{|l|}{ LANDMARKS } \\
\hline NRP_SKM & Density of religious places & (c) & 3.312 & 4.579 \\
\hline NHP_SKM & Density of historical places & (c) & 0.228 & 0.800 \\
\hline \multicolumn{5}{|l|}{ TRANSPORT } \\
\hline NCS_SKM & Car sharing station density & (d) & 0.348 & 1.009 \\
\hline NMS_SKM* & Presence of metro stations within $500 \mathrm{~m}$ & (d) & 0.320 & 1.266 \\
\hline NAS_SKM & Bus station density & (d) & 24.185 & 13.361 \\
\hline NXS_SKM & Taxi station density & (d) & 1.065 & 1.767 \\
\hline NTS_SKM* & Presence of train stations within $500 \mathrm{~m}$ & (d) & 0.393 & 1.343 \\
\hline PAKM_SKM & Rate of pedestrian areas & $(\mathrm{c}),(\mathrm{d})$ & 0.008 & 0.020 \\
\hline \multicolumn{5}{|c|}{ CULTURAL OFFERINGS } \\
\hline $\mathrm{NL}$ & Libraries density & (c) & 0.085 & 0.273 \\
\hline $\mathrm{NC}^{*}$ & Cinemas density & (c) & 0.580 & 2.140 \\
\hline $\mathrm{NM}^{*}$ & Museums density & (c) & 1.022 & 3.189 \\
\hline $\mathrm{NT}^{*}$ & Theatres density & (c) & 0.508 & 1.300 \\
\hline \multicolumn{5}{|l|}{ RETAIL } \\
\hline C_RST_SKM* & Retail cafè and restaurants & (d) & 70.953 & 86.210 \\
\hline C_FOD_SKM* ${ }^{*}$ & Retail_grocery stores & (d) & 53.186 & 64.320 \\
\hline C_BET_SKM* & Retail beauty & (d) & 43.042 & 43.521 \\
\hline C_MIX_SKM ${ }^{*}$ & Retail miscellaneous & (d) & 102.273 & 124.768 \\
\hline C_CLT_SKM ${ }^{*}$ & Retail_clothes & (d) & 30.562 & 57.387 \\
\hline C_FRE_SKM* & Retail freetime & (d) & 21.923 & 25.406 \\
\hline C_JWL_SKM ${ }^{*}$ & Retail jewellery and antiquities & (d) & 18.145 & 25.840 \\
\hline C_HOM_SKM ${ }^{*}$ & Retail_home & (d) & 14.091 & 18.215 \\
\hline C_ELC_SKM & Retail electronics & (d) & 11.800 & 16.762 \\
\hline C_VEH_SKM & Retail cars and fuel & (d) & 6.950 & 5.590 \\
\hline C_HEL_SKM* ${ }^{*}$ & Retail healthcare and pharmacies & (d) & 7.229 & 7.646 \\
\hline C_SUP_SKM* ${ }^{*}$ & Retail supermarkets & (d) & 2.840 & 3.408 \\
\hline C_FUN_SKM & Retail of funeral services & (d) & 0.827 & 1.546 \\
\hline NCB_SKM & Commercial centres & (c) & 15.599 & 15.129 \\
\hline NMK & Open air markets & (c) & 0.489 & 0.717 \\
\hline \multicolumn{5}{|c|}{ RESIDENTIAL SECTOR } \\
\hline NRB_SKM & Residential buildings & (b) & 340.402 & 264.880 \\
\hline RESHU & Almost occupied by one resident & (b) & 4603.040 & 3716.588 \\
\hline VHU_SKM & Vacant housing units & (b) & 471.644 & 467.029 \\
\hline NRESHU & Occupied by only not residents & (b) & 7.187 & 21.861 \\
\hline THU & Total housing units & (b) & 5081.871 & 4111.561 \\
\hline \multicolumn{5}{|c|}{ GREEN \& SPORTS } \\
\hline NSB_SKM* & Density of sport buildings & (c) & 6.192 & 7.735 \\
\hline GAKM_SKM* & Rate of public green areas & (c) & 1.187 & 1.037 \\
\hline \multicolumn{5}{|l|}{ EDUCATION } \\
\hline NUB $^{*}$ & University density & (c) & 0.542 & 2.067 \\
\hline NNSB & Nursery school density & (c) & 0.578 & 0.933 \\
\hline NS & School density & (c) & 7.002 & 6.249 \\
\hline \multicolumn{5}{|l|}{ HEALTHCARE } \\
\hline NH & Hospital density & (d) & 0.559 & 1.434 \\
\hline
\end{tabular}

${ }^{*}$ Variables subsequently selected and grouped by means of PCA.

highest and lowest values, and also, the metro line 1 track (represented in black) in the western part of the city is a border between highest and lowest values. Hierarchies defined by values and construction activities are transformed by the choropleth map of NeSI. In fact, Figure 8(c) shows different patterns in the city, and urban vibrancy seems to be concentrated in the centre, western, and southern part of the city, while in the hillside and in the north, it is rather absent. 


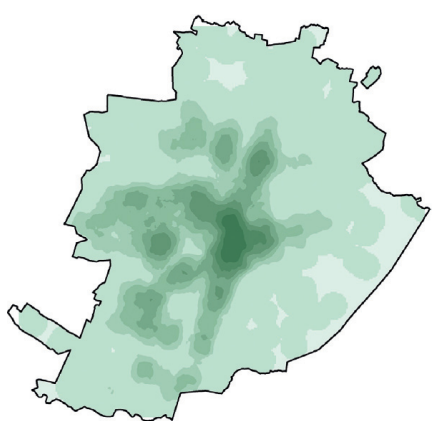

(a)

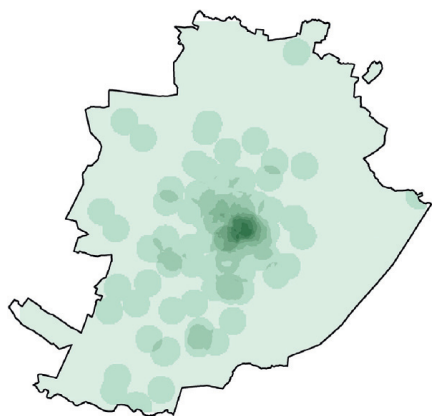

(b)

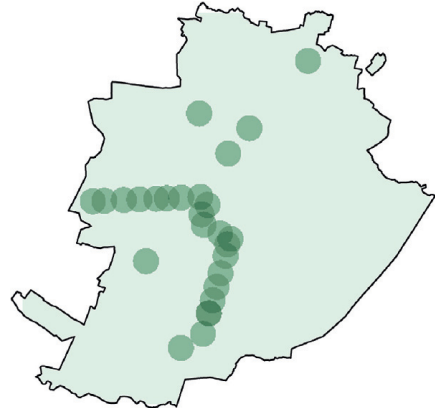

(c)

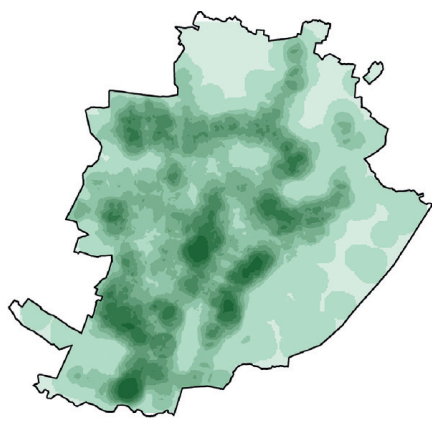

(d)

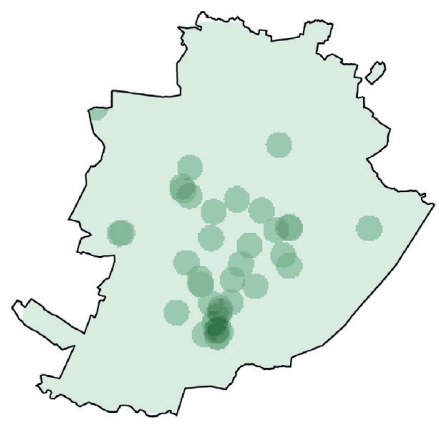

(e)

Figure 7: Five PCs: retail (PC1), Cultural Offer (PC2), Public Transport Station (PC3), Public Green and Sport Areas (PC4), and Public Healthcare (PC5) (source: author's elaboration). (a) PC1. (b) PC2. (c) PC3. (d) PC4. (e) PC5.

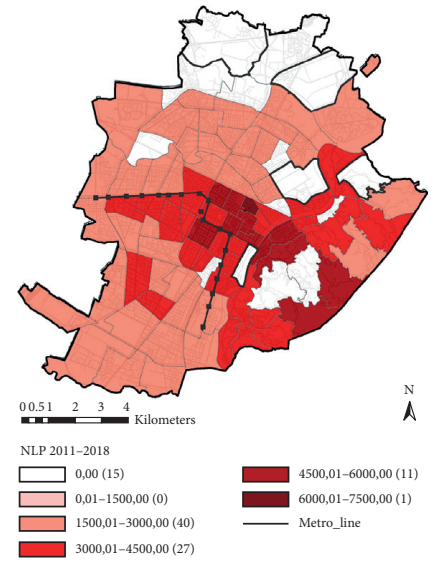

(a)

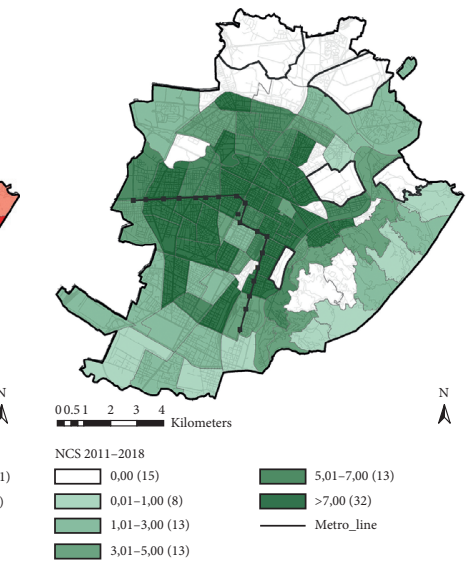

(b)

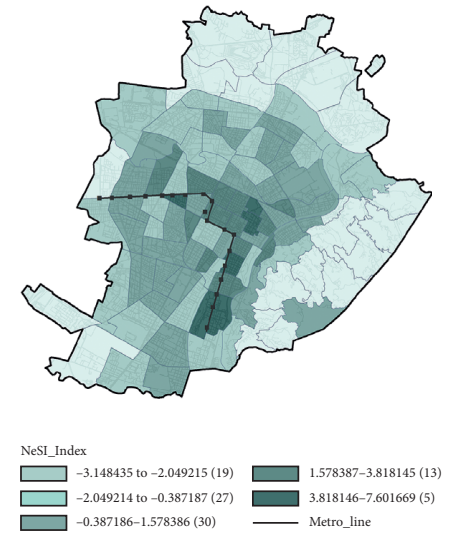

(c)

FIgURE 8: (a) Listing prices of new housing stock (NLP). (b) Construction Sites Density (CSD). (c) NeSI Mean values (source: author's elaboration).

\section{Results and Discussion}

5.1. Spatial Analyses by Data Point. In accordance with the aim of analysing the relationship between urban vibrancy and the listing prices of the new housing stock (NLP), we used the data points of the 2360 property listings offered in Turin between 2011 and 2018 which refer to 351 construction sites. To better analyse how the building/construction site features and the neighbourhood vibrancy influence the price formation process, only ordinary new housing units were taken into account, to estimate comparable values for each construction site. To explain the variability of listing prices, only the following extrinsic and intrinsic building characteristics were considered: construction site type (CST), year of construction (CY), Building Category (BC), Presence of Garage or Car Park (GRG), and the Neighbourhood Services Index (NeSI). Instead, intrinsic residential unit characteristics were excluded in this analysis for the following reasons: in the Italian real estate market, there are some important differences between the new housing stock and the existing one; the newly built housing units are homogeneous, concerning 
TABle 3: Pearson's Correlation Test (source: authors' elaboration).

\begin{tabular}{|c|c|c|c|c|c|c|}
\hline & NLP & CST & CY (dummy) & BC (dummy) & GRG (dummy) & NESI \\
\hline NLP & 1 & 0.179248584 & 0.05789702 & 0.61537324 & 0.07122211 & 0.34848031 \\
\hline CST & & 1 & 0.0874374 & 0.25146175 & -0.224033 & 0.30169269 \\
\hline CY (dummy) & & & 1 & 0.04938781 & 0.04010502 & 0.02592742 \\
\hline BC (dummy) & & & & 1 & -0.02111184 & 0.26285199 \\
\hline GRG (dummy) & & & & & 1 & -0.11136348 \\
\hline NESI & & & & & & 1 \\
\hline
\end{tabular}

some features such as the level of maintenance (new), the construction and technological quality, and the EPC level. Furthermore, in Italy, new residential units are usually listed and sold raw and unfinished; they initially have a common price per square meter that differs only for the allocation floor, the floor area, and the presence/absence of the panoramic view, while the fineness of finishes and the technological level are subsequently contracted apart. Therefore, if, on the one hand, the new residential unit characteristics are rather homogeneous and do not affect the price formation process at all, on the other hand, the building and locational features influence more the prices of the new housing stock than the prices of existing residential units.

To verify the absence of correlation between those variables, Pearson's and Spearman's correlation tests were performed, and Pearson's results, shown in Table 3, confirm the absence of a linear correlation between independent variables.

To assess spatial autocorrelation, Moran's Index was calculated, and it confirmed the presence of spatial autocorrelation in NLP values (Moran's I =0.587); Moran's Index scatterplot also confirmed a presence of positive autocorrelation and high-high and low-low clustering of NLP values (II and IV quadrants) (Figure 9).

5.1.1. Regression Models and Residuals Analysis: The Influences of the Extrinsic and Intrinsic Characteristics of the New Housing Stock on Listing Prices. Firstly, we performed an OLS model, and we tested it by means of Breush-Pagan and Koenker-Bassett tests, together with Moran Lagrange Multiplier tests (LM-lag and LM-error). Multicollinearity appears acceptable, while tests confirmed the presence of heteroskedasticity and spatial dependence. Since both LM tests and Local Moran's tests result significant, we performed both a spatial SLM and SEM regression models, and on the basis $R^{2}$, Log likelihood, and Akaike info criterion scores, we assumed the SLM model as more fitted. By means of GeoDa software [69], a Queen Contiguity-First Order Weight matrix $(W)[70]$ was generated and used in processing spatial models. The model presents the logarithm of NLP as an independent variable; NLP is calculated for each property listing by dividing the related price for the gross floor area. The use of the logarithm significantly enhanced the normality of the distribution of the variable. The selection process of the final explanatory variables started form the OLS Model Anova tests results and the use of the Akaike Information Criteria selection procedure (in $R$ StepAIC, direction = "both") to reach the best model with maximum explanatory power and lower number of variables. The

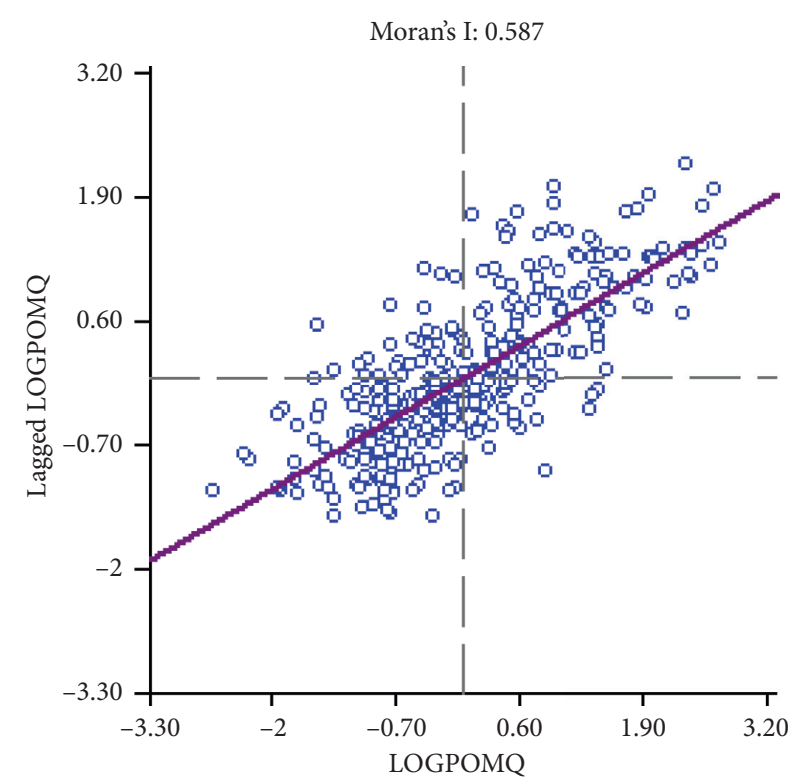

FIgURE 9: Moran's Index scatterplot on data points related to log NLP (Euro $/ \mathrm{m}^{2}$ ) (source: authors' elaboration).

following intrinsic building physical characteristics were used as independent variables: construction site type (CST), year of construction (CY), Building Category (BC), Presence of Garage or Car Park (GRG), and the Neighbourhood Services Index (NeSI) as a location proxy to measure the urban vibrancy (Table 4). Since the research is focused on the new housing stock, only building characteristics were analysed into the regression model, not considering the residential unit features.

Results showed that the model is able to explain $70 \%$ of the NLP variation and all the considered variables significantly influence NLP. Since we used the mean price for each construction site by considering only ordinary housing units, it is clear that the variability of the sample and the model has been reduced, but this choice is consistent with the research purposes, to better understand the influence of the characteristics of the buildings and the neighbourhood vibrancy.

In particular, it is evident that the NLP formation process is not much based on the type of intervention (newly built housing stock or totally refurbished existing buildings) probably because even if the buildings were totally refurbished or newly constructed, the quality level was almost homogeneous. In fact, thanks to the energy efficiency regulation, the heritage protection regulation, and the even more careful demand, in Turin, not only the newly built housing stock but also totally refurbished 
TABLE 4: Spatial lag model (SLM) to assess the relationship between NLP and extrinsic and intrinsic characteristics of the new housing stock (source: authors' elaboration).

\begin{tabular}{|c|c|c|c|}
\hline \multirow{3}{*}{ Variable } & \multicolumn{3}{|c|}{ New housing listing prices per square meter (LOG NLP) } \\
\hline & \multicolumn{3}{|c|}{ Spatial lag model (SLM) } \\
\hline & Coefficients & & \\
\hline Spatial coefficient $(W)$ & 0.704 & 0.000 & $* * *$ \\
\hline CST1-newly constructed & & & \\
\hline CST2-totally refurbished & 0.038 & 0.055 & . \\
\hline CY-2011 & 0.179 & 0.000 & $* * *$ \\
\hline CY-2012 & 0.163 & 0.000 & $* * *$ \\
\hline CY-2013 & 0.119 & 0.005 & $* *$ \\
\hline CY-2014 & 0.119 & 0.001 & $* * *$ \\
\hline CY-2015 & 0.059 & 0.105 & \\
\hline CY-2016 & 0.080 & 0.031 & * \\
\hline CY-2017 & & & \\
\hline CY-2018 & 0.879 & 0.034 & * \\
\hline BC1-economic & & & \\
\hline BC2-medium & 0.073 & 0.075 & . \\
\hline BC3-noble & 0.193 & 0.000 & $* * *$ \\
\hline BC4-prestigious & 0.389 & 0.000 & $* * *$ \\
\hline GRG0-box or private car park absent & & & \\
\hline GRG1-box or private car park present & 0.064 & 0.001 & $* * *$ \\
\hline $\mathrm{NeSI}$ (numerical) & 0.020 & 0.000 & $* * *$ \\
\hline Constant & 2.079 & 0.000 & $* * *$ \\
\hline Number of observations & 351 & & \\
\hline Log likelihood & 129.905 & & \\
\hline AIC & -229.81 & & \\
\hline $\mathrm{R}$ square & 0.70 & & \\
\hline Breush-Pagan test & 24.766 & 0.024 & \\
\hline Likelihood ratio test & 189.608 & 0.000 & \\
\hline
\end{tabular}

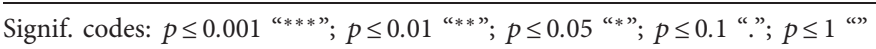

existing buildings currently respond to high-quality standards (high energy efficiency levels and the presence of high-level technologies, materials, and home automation), despite the presence of a series of requirements due to the constraints related to the existing housing stock (preservation requirements, relationship with the neighbourhood, and formal limits).

Moreover, it is interesting to notice that NLP depends on some building features: the Construction Year (CY), the Presence of Garage or Car Park (GRG), and the Building Category (economic, medium, noble, or prestigious), which reflects the economic-financial investments for construction works, as well as the quality standards finishes, the market segment, and the final users' willingness to pay. The main intrinsic features of the building able to influence NLP are the newness (CY2018) and the spatial coefficient $(W)$.

Furthermore, results showed that NLP is positively influenced by the presence of neighbourhood services nearby (NeSI) that can be considered an extrinsic feature that implicitly represents the location variable.

Finally, a residuals analysis illustrated that the model should not be biased and the autocorrelation among residuals is almost absent (Figure 10).

The SLM residuals scatterplot (Figure 10(a)) highlighted that the spatial component was probably the main factor for variables autocorrelation since it is quite absent between residuals $(-0.033)$ so it is not able to mislead significance tests or to define suboptimal model prediction. In fact, the predicted values of the model, represented by means of quantile maps in Figure 10(b), highlight clusters of higher values (brown-coloured) in the city centre and on the hillside, while in the northern part of the city, there is a bigger cluster of lower values (light yellow-coloured). Therefore, it is possible to conclude that the SLM model processed had a good fit with reality and a quite comparable prediction power.

5.2. Spatial Analyses with Lattice Data in the 94 SZ. The analysis of the real estate market of new housing stock cannot be limited to property prices since the dynamism of the construction activity represents a key factor to be considered in the monitoring process. Therefore, spatial analyses were performed to focus on the spatial components and effects of the neighbourhood services density in the $94 \mathrm{SZ}$ in relation to the Construction Site Density (CSD) variable.

Initially, the NeSI and its 5 PCs were analysed, and their correlation with the CSD was tested by means of Pearson's correlation test. Results showed a strong correlation between the CSD and PC1 (0.801) and, as expected, the absence of a correlation between each component (PC) and the others (Table 5).

Subsequently, spatial dependence was calculated to measure the local spatial association level between values of 


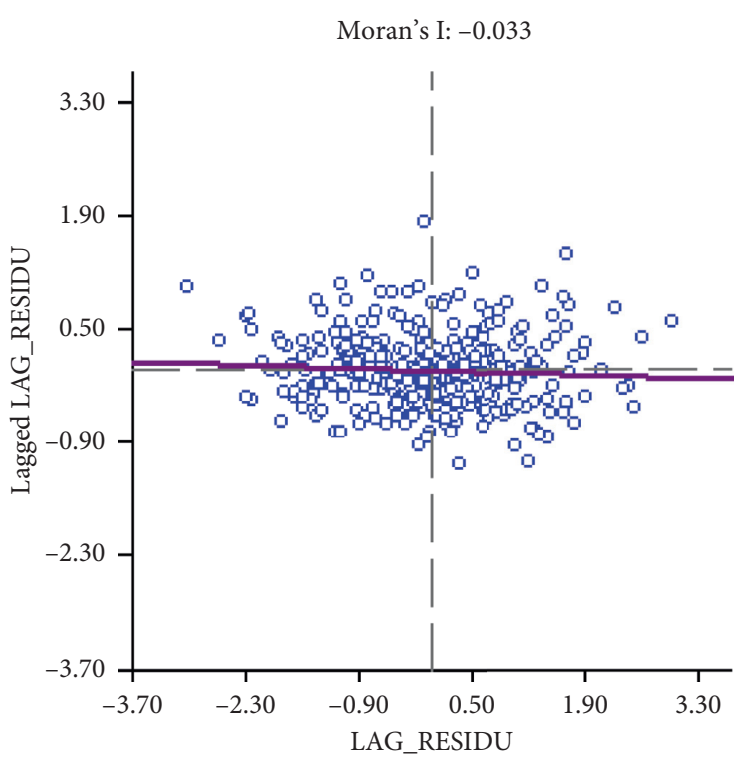

(a)

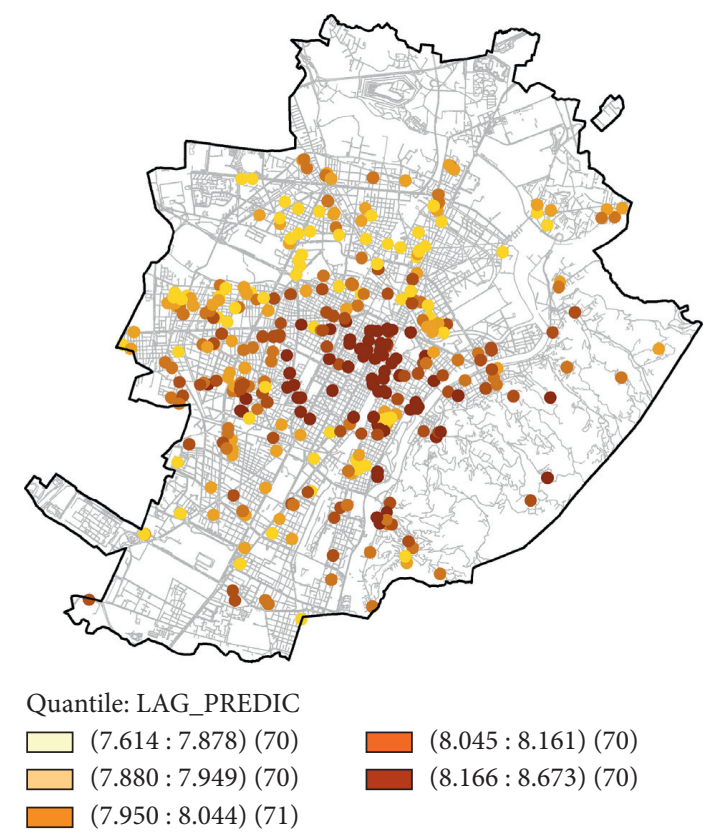

(b)

Figure 10: Residuals analysis (regression Table 4): (a) NLP SLM residuals Moran scatterplot; (b) NLP SLM predicted quantile map (source: authors' elaboration).

TABLE 5: Pearson's correlation test (source: authors' elaboration).

\begin{tabular}{|c|c|c|c|c|c|c|c|}
\hline Variable & CSD & NESI & PC1 & PC2 & PC3 & PC4 & PC5 \\
\hline CSD & 1.000 & 0.464 & 0.801 & 0.155 & 0.166 & -0.045 & -0.039 \\
\hline NESI & & 1.000 & 0.447 & 0.447 & 0.447 & 0.447 & 0.447 \\
\hline PC1 & & & 1.000 & 0.000 & 0.000 & 0.000 & 0.000 \\
\hline PC2 & & & & 1.000 & 0.000 & 0.000 & 0.000 \\
\hline PC3 & & & & & 1.000 & 0.000 & 0.000 \\
\hline PC4 & & & & & & 1.000 & 0.000 \\
\hline PC5 & & & & & & & 1.000 \\
\hline
\end{tabular}

each territorial unit and the value of the neighbouring ones. In particular, the CSD and NeSI were examined by calculating Moran's I and LISA statistics (Figure 11).

Moran's Index scatterplots in Figure 11 showed the presence of a positive autocorrelation of the CSD and NeSI across the SZ, since most of the observations were located in the II and IV quadrants. The highest value of autocorrelation was observed for the NeSI (Moran's I = 0.433), followed by the CSD (Moran's I =0.365) and a significance calculation (99 permutation) on the basis of Monte Carlo statistics confirmed the significance of the clusters, with a $p$ value between 0.001 and 0.05 .

LISA maps suggested striking geographic clustering of the CDS in the central, northern, and eastern urban areas (a): the "low-low" cluster is located in the northern and eastern area (hillside) of the city, representing a positive spatial autocorrelation of lower values, while the "high-high" cluster, located in the city centre, represented the positive spatial autocorrelation of high values. Furthermore, it is interesting to notice the similar clustering of the CSD and NeSI (b), so that it is evident that developers and construction companies prefer to invest in vibrant areas, such as the city centre, rather than on the hillside where, although housing prices are high (Figure 11(a)), the neighbourhood services are limited.

5.2.1. Regression Models and Residuals Analysis: The Influence of Neighbourhood Services on Construction Site Density. The regression model outlined in the methodology section was applied to assess the influence of the NeSI and its 5 PCs on the density of construction sites (CSD). Two OLS models were performed considering the CSD as a dependent variable and the NeSI (first model) and the 5 PCs (second model) as independent variables. Findings of the first model suggested that the NeSI has a significant and positive influence in explaining the CSD $\left(\right.$ SLM $\left.R^{2}=0.34\right)$, so that it deserves to be more deeply analysed by separately considering the influence of the 5 PCs. In the second model, tests (LM) result was not significative, so the null hypothesis is not rejected, and error terms of the 

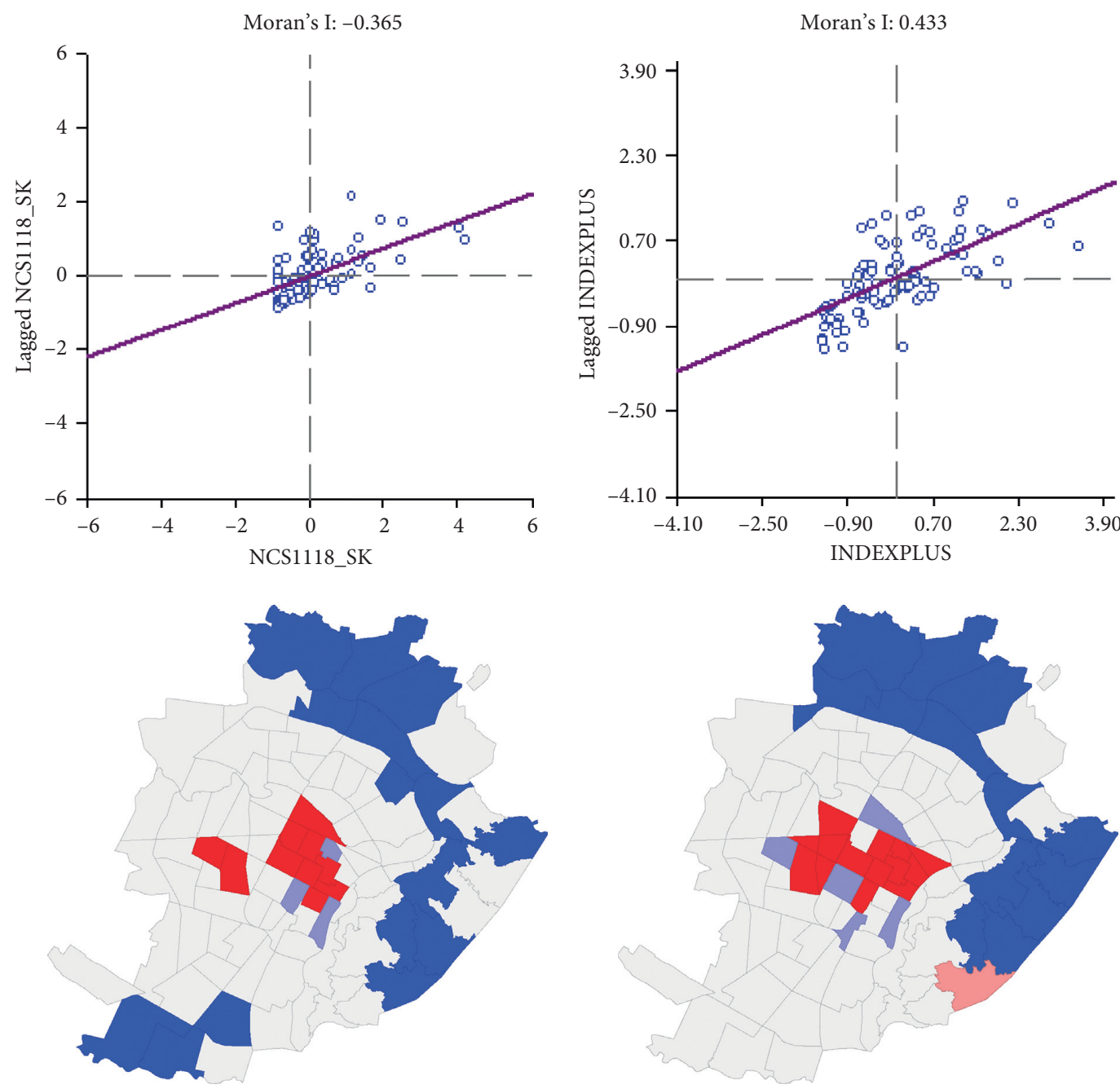

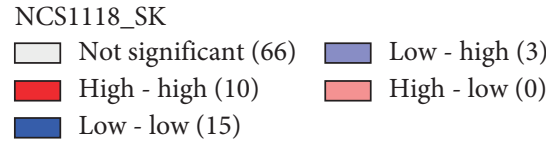

(a)
INDEXPLUS

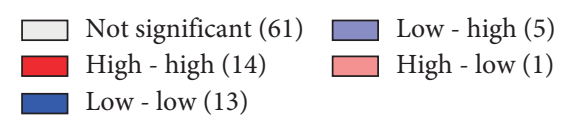

(b)

FIGURE 11: Moran's Index scatterplot and Local Indicator of Spatial Association (LISA) cluster maps in the 94 SZ of Turin, depicting spatial clustering and spatial outliers: (a) CSD $\left(\mathrm{n} / \mathrm{km}^{2}\right)$; (b) NeSI (source: authors' elaboration).

regression may be randomly distributed, so the OLS model seems unbiased (Table 6).

Table 6 shows the results of the second OLS regression model: the presence of retail activities (PC1), the cultural offer (PC2), and the proximity to public transports stations (PC3) have a positive and significant influence on the CSD. Therefore, it is possible to hypothesize that the homogeneous coverage of green urban areas in the city is not captured by the model as the presence of healthcare centres such as hospitals and clinics.

5.2.2. Regression Models and Residuals Analysis: The Influence of Retail Activities on the Construction Site Density. The results achieved and presented in Table 6 provide compelling evidence that the presence of a high concentration of retail activities influences CSD, even if with substantial differences between the hillside of the city (characterized by a low density of retail activities and by the highest housing prices of the city) and the city centre (where both housing prices and the density of retail activities are rather high).

For this reason, we focused the attention on the retail sector (PC1-Retail), able to explain more than $50 \%$ of the variance of the whole sample, and we performed a new regression analysis with the CSD as a dependent variable and different typologies of the retail sector, presented in Table 2, as independent variables, in order to understand which product sectors have a higher influence on construction activities. An OLS model was initially performed, and after the presence of spatial dependence between the analysed 
TABLE 6: Ordinary Least Squares (OLS) model and to assess the relationship between the CSD and the 5 PCs (source: authors' elaboration).

\begin{tabular}{|c|c|c|c|}
\hline \multirow{3}{*}{ Variable } & \multicolumn{3}{|c|}{ Construction sites density (CSD) } \\
\hline & \multicolumn{3}{|c|}{ Ordinary least square (OLS) } \\
\hline & Coefficients & & \\
\hline Spatial coefficient $(W) /$ Lambda & - & - & \\
\hline PC1-retail & 4.508 & 0.000 & $* * *$ \\
\hline PC2-cultural offer & 0.870 & 0.009 & $* *$ \\
\hline PC3-Public transport stations & 0.932 & 0.006 & $* *$ \\
\hline PC4-Public green and sports areas & -0.254 & 0.444 & \\
\hline PC5-healthcare & -0.220 & 0.507 & \\
\hline Constant & 4.867 & 0.000 & $* * *$ \\
\hline Number of observations & 94 & & \\
\hline Log likelihood & -239.192 & & \\
\hline AIC & 490.384 & & \\
\hline R Square & 0.697 & & \\
\hline Breush-Pagan test & 13.136 & 0.022 & \\
\hline Jarque-Bera test & 65.756 & 0.000 & \\
\hline
\end{tabular}

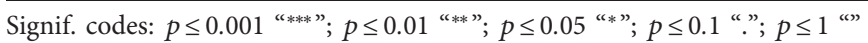

TABLE 7: SER model to assess the relationship between the CDS and different typologies of the retail activities (source: authors' elaboration).

\begin{tabular}{lcc}
\hline Variable & & $\begin{array}{c}\text { Construction site density (CS) } \\
\text { Spatial error model (SEM) }\end{array}$ \\
\hline C_RST_SKM & Coefficients & 0.000 \\
P_FOD_SKM & 0.074672 & 0.006 \\
C_BET_SKM & -0.06815 & 0.068 \\
C_MIX_SKM & 0.046344 & 0.984 \\
C_CLT_SKM & -0.00027 & 0.17 \\
C_FRE_SKM & -0.02253 & 0.143 \\
C_JWL_SKM & 0.065593 & 0.973 \\
C_HOM_SKM & -0.00131 & 0.000 \\
C_HEL_SKM & 0.188209 & 0.024 \\
C_SUP_SKM & -0.26819 & 0.2 \\
Constant & -0.2013 & 0.521 \\
Lambda & 0.352554 & 0.044 \\
Number of observations & 0.296687 & \\
Log likelihood & 94 & $*$ \\
AIC & -224.531 & \\
R square (adjusted) & 471.063 & \\
Breush-pagan test & 0.782 & \\
Likelihood ratio test & 28.5440 & 0.00148 \\
\hline
\end{tabular}

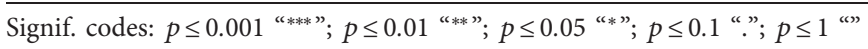

variables was confirmed by LM tests, a Spatial Error Model (SEM) was performed to manage the spatial component of the variables (Table 7).

First of all, results showed that the model has a good fit $\left(R^{2}=0.78\right)$ and that household items (C_HOM_SKM) had the higher marginal coefficient. In addition, restaurants (C_RST_SKM), grocery (C_FOD_SKM), and healthcare (C_HEL_SKM) shops result significant in the explanation of the density pattern of housing construction sites. The great influence of the presence of a restaurant is emblematic, since this kind of retail activity is the only one able to generate urban vibrancy, in terms of number of people in and around streets or neighbourhoods at different times of the day and night. The retail sector in Turin mainly consists of miscellaneous shops, restaurants, cafés, food shops, and commercial activities connected to beauty. The other retail categories (clothing, free time and leisure, jewellery, home, healthcare stores, and supermarkets) are fewer and less concentrated. Nevertheless, it is confirmed that the presence/concentration of restaurants and shops related to the basic services (home, food, and healthcare) are probably fundamental locational features that contractor and investors take into account in their decision process.

Finally, to verify the model, residual and predicted values analyses were performed (Figure 12).

The residuals scatterplot (Figure 12(a)) highlighted that the spatial autocorrelation is quite absent between residuals 


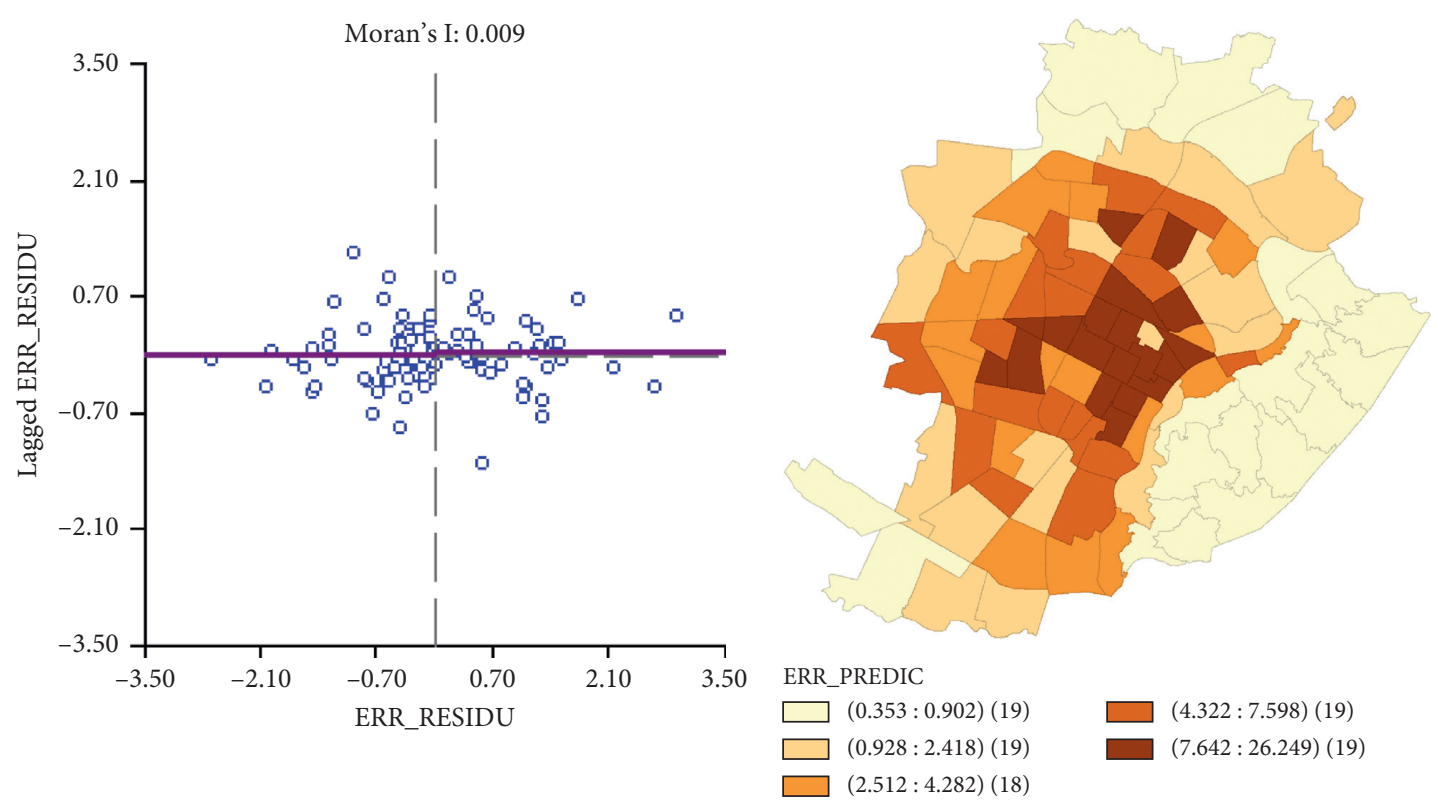

(a)

(b)

FIGURE 12: SER model residuals scatterplot (a) and predicted value Lisa clustering (b) (source: authors' elaboration).

and it is not able to mislead significance tests or define suboptimal model prediction. In fact, the predicted values of the model, represented by means of quantile maps in Figure 12(b), highlight a very similar pattern to the natural breaks map of real values of the CSD in Figure 4. In both maps, there are clusters of higher values (brown-colored) in the city centre with some extension toward the west and south along the main infrastructure axes, while in the northern and eastern part of the city, there are bigger clusters of lower values (yellow-colored).

\section{Conclusions and Discussion}

Assuming from the literature that activity intensity can be used as a proxy to measure urban vibrancy, a methodological approach was developed to study how the high concentration and diversity of land-use configurations and neighbourhood services can influence the real estate market of new housing stock.

This research was developed assuming the results achieved in a previous/sister study that considered a series of neighbourhood services (such as public transports, retail activities, schools, museums, theatres, green areas, sport buildings, and hospitals) and created a Neighbourhood Services Index (NeSI) to spatially analyse its influence on housing prices of existing housing stock [7]. This study goes further since it considered the housing prices of new housing stock and the construction site density and their relationship with the NeSI and its Principal Components (PCs). The attractiveness and vibrancy of urban areas were analysed by performing spatial analyses and spatial regression models on data related to a medium former industrial city in northern Italy.
Results highlighted the presence of a positive spatial dependence in the variables analysed: NLP, CSD, and NeSI. In particular, LISA clusters showed similar patterns of CSD and NeSI values, which means that developers and construction companies prefer to invest in vibrant areas, rather than in urban areas where, although housing prices are high, the neighbourhood services are limited.

Furthermore, regression models result (OLS, SLM, and SEM) highlighted that the NeSI had a significant and positive influence in explaining both the NLP and CSD. Therefore, in studying the relations between urban vibrancy and the real estate market of new housing stock, the housing construction dynamism is as relevant as property prices. The housing listings are strictly related to the specific peculiarity of the intervention, given by a set of intrinsic building features, and also location and extrinsic features have a role in the explanation of prices. The SLM confirmed that the NLP is primarily related to the construction site typology, the year of construction, and the building category and is secondly influenced by the presence urban services nearby. Deepening urban vibrancy features, an OLS model showed the relation of NCS with the 5 PCs of the NeSI and the density of retail activities emerged as the main factor above the analysed neighbourhood services able to significantly and positively explain the variability of construction site density. This confirms that the presence of neighbourhood services fosters the construction activity, leading real estate developers to start construction sites.

Future research will be addressed to define different submarkets to be separately analysed by means of local models; therefore, in the future, the NeSI and its influence on housing price will be differently estimated at different points over space. 
The results achieved in this study can help public and private subjects not only to analyse the specific urban development and real estate market of the city of Turin but also to deal with some important aspects related to urban complexity that can support the analysis of other urban contexts. The spatial analyses performed here and tested in the city of Turin can support both public and private bodies operating in other cities to identify the most and least attractive and vibrant urban areas and to address their investment decisions and development strategies. Assuming the private bodies' perspectives, such as the construction companies, it is fundamental to identify the right market segments, as well as the right locations within the city, in order to maximize the projects profitability and minimize the risks related to the real estate market. On the other hand, the public administrations need to identify the least attractive urban areas in order to improve them by means of specific infrastructural works or the activation of strategic regeneration projects. The urban areas where Public Administrations foster the development of new housing stock aspire to be real spillovers for the urban economy, but often lack in efficient connections with other parts of the city and in neighbourhood services that make urban areas properly equipped, attractive, and vibrant. For these reasons, the identification of those neighbourhood services able to attract investors and real estate developers represents a key factor to understand how the city is developing and to guide different territorial marketing strategies for each specific urban area and its related submarkets.

Therefore, the methodological approach presented in this study can help to find out new factors and rules that influence the urban development in the transformation of classical paradigms, in terms of socioeconomic processes and land-use spatial hierarchies. New spatial hierarchies can be identified by studying the economic and social phenomena and by understanding those factors affecting morphology and functions of the current redeveloping cycle of urban areas. In this perspective, the study of the real estate market of new housing stock is crucial since it reflects both the interests of private bodies to invest in construction works and the final users' behaviours and purchasing criteria. It represents a key factor to be studied in relation to urban vibrancy and city life, in terms of equity/justness of property prices, the shorting of bargaining timing, the decrease of unsold housing units, and the increase of public and private investors. Moreover, the level of productivity of the construction industry, measured by means of the CSD variable, is an extremely interesting factor that deserves to be monitored and analysed jointly with property prices and urban vibrancy. Understanding which neighbourhood services are able to influence the real estate market of new housing stock and the related choices of private investors and consumers really supports public bodies in cities development, by correctly addressing territorial marketing strategies in specific urban areas and by improving the whole urban attractiveness and vibrancy.

\section{Limitation of the Study}

One of the key limitations of this study, even if justified by the literature, was the necessity of using listing prices as a proxy for the actual transaction prices, due to the unavailability of public data about transaction prices in the Italian context.

Moreover, being an explorative step of a research field regarding the new housing stock, we demand to future development the passage from Global Spatial Statistics as the SLM and the SEM to local ones such as Geographical Weight Regressions models.

\section{Data Availability}

POIs data of the urban built and green environment, used to support the findings of this study, are open data available on the following web pages: ISTAT (https://www.istat.it/en/); Municipality of Turin Geoportal (http://geoportale.comune. torino.it/web/), and Piedmont Region Geoportal (http:// www.geoportale.piemonte.it/cms/). These data are also available from the corresponding author upon request. TREMO data (housing listing prices and related characteristics), used to support the findings of this study, have not been made available because of third-party rights.

\section{Conflicts of Interest}

The authors declare that there are no conflicts of interest regarding the publication of this paper.

\section{References}

[1] J. Jacobs, The Death and Life of Great American Cities. The Failure of Town Planning, Random House, New York, NY, USA, 1961.

[2] J. Jacobs, The Life of Cities, Random House, New York, NY, USA, 1969.

[3] J. Montgomery, "Urban vitality and the culture of cities," Planning Practice \& Research, vol. 10, 1995.

[4] J. Montgomery, "Making a city: urbanity, vitality and urban design," Journal of Urban Design, vol. 3, 1998.

[5] C. Wu, X. Ye, F. Ren, and Q. Du, "Check-in behaviour and spatio-temporal vibrancy: An exploratory analysis in Shenzhen, China," Cities, vol. 77, pp. 104-116, 2018.

[6] Y. Yue, Y. Zhuang, A. G. O. Yeh, J.-Y. Xie, C.-L. Ma, and Q.-Q. Li, "Measurements of POI-based mixed use and their relationships with neighbourhood vibrancy," International Journal of Geographical Information Science, vol. 31, no. 4, pp. 658-675, 2017.

[7] A. Barreca, R. Curto, and D. Rolando, "Urban vibrancy: an emerging factor that spatially influences the real estate market," Sustainability, vol. 12, no. 1, pp. 346-379, 2020.

[8] A. Barreca, R. Curto, and D. Rolando, "Assessing social and territorial vulnerability on real estate submarkets," Buildings, vol. 7, no. 4, 2017.

[9] A. Barreca, R. Curto, and D. Rolando, "Housing vulnerability and property prices: spatial analyses in the turin real estate market," Sustain, vol. 10, no. 9, 2018. 
[10] J. M. Smith, "Multibase integrating heterogeneous distributed database systems." in AFIPS Conference Proceedings, Chicago, IL, USA, May 1981.

[11] J. LeSage and R. K. Pace, Introduction to Spatial Econometrics, CRC Press, Boca Raton, FL, USA, 2009.

[12] S. Lu, Y. Huang, C. Shi, and X. Yang, "Exploring the associations between urban form and neighborhood vibrancy: a case study of Chengdu, China," ISPRS International Journal of Geo-Information, vol. 8, no. 4, p. 165, 2019.

[13] C. Wu, X. Ye, F. Ren, Y. Wan, P. Ning, and Q. Du, "Spatial and social media data analytics of housing prices in Shenzhen, China," PLoS One, vol. 11, 2016.

[14] M. Winters, M. Brauer, E. M. Setton, and K. Teschke, "Built environment influences on healthy transportation choices: bicycling versus driving," Journal of Urban Health, vol. 87, 2010.

[15] A. G. Nicodemus, "Fuzzy vibrancy: creative placemaking as ascendant US cultural policy," Cultural Trends, vol. 22, no. 34, pp. 213-222, 2013.

[16] M. J. Stern and S. C. Seifert, "Cultural clusters: the implications of cultural assets agglomeration for neighborhood revitalization," Journal of Planning Education and Research, vol. 29, no. 3, pp. 262-279, 2010.

[17] S. Rosen, "Hedonic prices and implicit markets: product differentiation in pure competition," in Revealed Preference Approaches to Environmental Valuation Volumes I and II, pp. 5-26, Taylor \& Francis, Oxfordshire, UK, 2019.

[18] C. Brunsdon, A. S. Fotheringham, and M. E. Charlton, "Geographically weighted regression: a method for exploring spatial nonstationarity," Geographical Analysis, vol. 28, no. 4, pp. 281-298, 2010.

[19] A. S. Fotheringham, M. E. Charlton, and C. Brunsdon, "Geographically weighted regression: a natural evolution of the expansion method for spatial data analysis," Environment and Planning A: Economy and Space, vol. 30, no. 11, pp. 1905-1927, 1998.

[20] F. Yuan, J. Wu, Y. D. Wei, and L. Wang, "Policy change, amenity, and spatiotemporal dynamics of housing prices in Nanjing, China," Land Use Policy, vol. 75, 2018.

[21] T. W. Sharkova, V. Irina, and Sanchez, An Analysis of Neighborhood Vitality: The Role of Local Civic Organizations an Analysis of Neighborhood Vitality, Portland State University, Portland, OR, USA, 2017.

[22] H. Wen, Y. Zhang, and L. Zhang, "Assessing amenity effects of urban landscapes on housing price in Hangzhou, China," Urban Forestry \& Urban Greening, vol. 14, no. 4, pp. 10171026, 2015.

[23] X. Dai, X. Bai, and M. Xu, "The influence of Beijing rail transfer stations on surrounding housing prices," Habitat International, vol. 55, pp. 79-88, 2016.

[24] M. Jang and C. D. Kang, "Retail accessibility and proximity effects on housing prices in Seoul, Korea: a retail type and housing submarket approach," Habitat International, vol. 49, 2015.

[25] H. Wen and Y. Tao, "Polycentric urban structure and housing price in the transitional china: evidence from Hangzhou," Habitat International, vol. 46, 2015.

[26] Y. Ye, D. Li, and X. Liu, "How block density and typology affect urban vitality: an exploratory analysis in Shenzhen, China," Urban Geography, vol. 39, 2018.

[27] C. Jacobs-Crisioni, P. Rietveld, E. Koomen, and E. Tranos, "Evaluating the impact of land-use density and mix on spatiotemporal urban activity patterns: an exploratory study using mobile phone data," Environment and Planning A: Economy and Space, vol. 46, no. 11, pp. 2769-2785, 2014.

[28] S. Li, X. Ye, J. Lee, J. Gong, and C. Qin, "Spatiotemporal analysis of housing prices in China: a big data perspective," Applied Spatial Analysis and Policy, vol. 10, no. 3, pp. 421-433, 2017.

[29] I. Zambon and L. Salvati, "Metropolitan growth, urban cycles and housing in a Mediterranean country, 1910s-2010s," Cities, vol. 95, 2019.

[30] D. L. Barkley, L. H. Klaassen, W. T. M. Molle, and J. H. P. Paelinck, "Dynamics of urban development," Southern Economic Journal, vol. 2, 1982.

[31] L. Van Den Berg, R. Drewett, L. H. Klaassen, A. Rossi, and C. H. T. Vijverberg, "Urban Europe Vol. 1: a study of growth and decline," Urban, vol. 1, 1981, https://journals.sagepub. com/home/eur.

[32] V. G. Morelli, K. Rontos, and L. Salvati, "Between suburbanisation and re-urbanisation: revisiting the urban life cycle in a mediterranean compact city," Urban Research \& Practice, vol. 7, 2014.

[33] F. Kroll and N. Kabisch, "The relation of diverging urban growth processes and demographic change along an urbanrural gradient," Population, Space and Place, vol. 18, 2012.

[34] M. Kasanko, "Are European cities becoming dispersed?. A comparative analysis of 15 European urban areas," Landscape and Urban Planning, vol. 77, 2006.

[35] S. Buzar, P. Ogden, R. Hall, A. Haase, S. Kabisch, and A. Steinführer, "Splintering urban populations: emergent landscapes of reurbanisation in four European cities," Urban Studies, vol. 44, 2007.

[36] L. Salvati, "The dark side of the crisis: disparities in per capita income (2000-12) and the urban-rural gradient in Greece," Tijdschrift voor economische en sociale geografie, vol. 107, 2016.

[37] P. M. Delladetsima, "The emerging property development pattern in Greece and its impact on spatial development," European Urban and Regional Studies, vol. 13, 2006.

[38] R. H. Edelstein and D. Tsang, "Dynamic residential housing cycles analysis," The Journal of Real Estate Finance and Economics, vol. 35, no. 3, pp. 295-313, 2007.

[39] Z. Yang and S. Wu, "Land acquisition outcome, developer risk attitude and land development timing," The Journal of Real Estate Finance and Economics, vol. 59, no. 2, pp. 233-271, 2019.

[40] D. Genesove and C. Mayer, "Loss aversion and seller behavior: evidence from the housing market," The Quarterly Journal of Economics, vol. 116, 2001.

[41] A. W. Evans, "The property market: ninety per cent efficient?" Urban Studies, vol. 32, no. 1, pp. 5-29, 1995.

[42] K. E. Case and R. J. Shiller, "The efficiency of the market for single-family homes," No. w2506, National Bureau of Economic Research, Cambridge, MA, USA, 1989.

[43] P. Morano, F. Tajani, and M. Locurcio, "Land use, economic welfare and property values: an analysis of the interdependencies of the real-estate market with zonal and socio-economic variables in the municipalities of Apulia region (Italy)," International Journal of Agricultural and Environmental Information Systems, vol. 6, 2015.

[44] R. J. G. M. Florax and A. J. van der Vlist, "Spatial econometric data analysis: moving beyond traditional models," International Regional Science Review, vol. 26, 2003.

[45] L. Chun-Chang, L. Chi-Ming, and H. Hui-Chuan, "The impact of a mass rapid transit system on neighborhood housing prices: an application of difference-in-difference and spatial 
econometrics," Real Estate Management and Valuation, vol. 28, no. 1, pp. 28-40, 2020.

[46] D. Wittowsky, J. Hoekveld, J. Welsch, and M. Steier, "Residential housing prices: impact of housing characteristics, accessibility and neighbouring apartments - a case study of Dortmund, Germany," Urban, Planning and Transport Research, vol. 8, no. 1, pp. 44-70, 2020.

[47] L. Yao, G. Gu, and J. W.-E. Geography, "The spatial effect of building new housing in Zhengzhou City: based on the spatial econometrics model," 2014, http://en.cnki.com.cn.

[48] S. Chen, D. Zhuang, and H. Zhang, "gis-based spatial autocorrelation analysis of housing prices oriented towards a view of spatiotemporal homogeneity and nonstationarity: a case study of Guangzhou, China," Complexity, vol. 2020, Article ID 1079024, 16 pages, 2020.

[49] R. Cellmer, A. Cichulska, and M. Bełej, "Spatial analysis of housing prices and market activity with the geographically weighted regression," ISPRS International Journal of GeoInformation, vol. 9, no. 6, p. 380, 2020.

[50] F. Yuan, Y. D. Wei, and J. Wu, "Amenity effects of urban facilities on housing prices in china: accessibility, scarcity, and urban spaces," Cities, vol. 96, 2020.

[51] S. Mathur, "Impact of transit stations on house prices across entire price spectrum: a quantile regression approach," Land Use Policy, vol. 99, 2020.

[52] R. Curto, E. Fregonara, and P. Semeraro, "Asking prices vs market prices: an empirical analysis," Italian Territory, vol. 1, pp. 53-72, 2012.

[53] P. Semeraro and E. Fregonara, "The impact of house characteristics on the bargaining outcome," Journal of European Real Estate Research, vol. 6, 2013.

[54] R. Curto, E. Fregonara, and P. Semeraro, "A spatial analysis for the real estate market applications," in Studies in Systems, Decision and ControlSpringer, Berlin, Germany, 2017.

[55] E. Fregonara, R. Giordano, D. G. Ferrando, and S. Pattono, "Economic-environmental indicators to support investment decisions: a focus on the buildings' End-Of-Life Stage," Buildings, vol. 7, 2017.

[56] A. Barreca, R. Curto, and D. Rolando, "Location and real estate values: a study of the segmentation of the Microzones of Turin," Italian territory, vol. 2, pp. 49-71, 2017.

[57] R. Curto and E. Fregonara, "Un sistema informativo territoriale per l'osservazione del mercato immobiliare a supporto dei catasti urbani e della gestione del territorio," Aestimum, pp. 24-42, 2002.

[58] M. F. Goodchild, Spatial Autocorrelation. Concepts and Techniques in Modern Geography 47', Wordpress, San Francisco, CA, USA, 1986.

[59] S. Basu and T. G. Thibodeau, "Analysis of spatial autocorrelation in house prices," The Journal of Real Estate Finance and Economics, vol. 17, 1998.

[60] S. Ismail, "Spatial autocorrelation and real estate studies: a literature review," Malaysian Journal of Real Estate, vol. 1, no. 1, pp. 1-13, 2006.

[61] M. Cajias and S. Ertl, "Spatial effects and non-linearity in hedonic modeling," Journal of Property Investment \& Finance, vol. 36, 2018.

[62] M. C. Schmidtlein, R. C. Deutsch, W. W. Piegorsch, and S. L. Cutter, "A sensitivity analysis of the social vulnerability index," Risk Analysis, vol. 28, no. 4, pp. 1099-1114, 2008.

[63] T. S. Breusch and A. R. Pagan, "A simple test for heteroscedasticity and random coefficient variation," Econometrica, vol. 47, 1979.
[64] L. Anselin and D. A. Griffith, "Do spatial effect really matter in regression analysis?” Papers in Regional Science, vol. 65, 1988.

[65] R. Haining, S. Wise, and J. Ma, "Exploratory spatial data analysis," Journal of the Royal Statistical Society: Series D (The Statistician), vol. 47, no. 3, pp. 457-469, 1998.

[66] S. C. Bourassa, E. Cantoni, and M. Hoesli, "Predicting house prices with spatial dependence: a comparison of alternative methods," Journal of Real Estate Research, vol. 32, no. 2, pp. 139-159, 2010.

[67] M. Wilhelmsson, "Spatial models in real estate economics," Housing, Theory and Society, vol. 19, no. 2, pp. 92-101, 2002.

[68] L. Seymour, "Spatial data analysis: theory and practice," Journal of the American Statistical Association, 2005.

[69] L. Anselin, I. Syabri, and Y. Kho, "GeoDa: an introduction to spatial data analysis," Geographical Analysis, vol. 38, 2006.

[70] L. Anselin and A. Bera, "Spatial dependence in linear regression models with an introduction to spatial econometrics," in Handbook of Applied Economic StatisticsTaylor \& Francis Group, Oxfordshire, UK, 1998. 